\title{
Phylogenetic revision of the psammophilic Trogloderus LeConte (Coleoptera: Tenebrionidae), with biogeographic implications for the Intermountain Region
}

\author{
M. Andrew Johnston Corresp. 1 \\ ${ }^{1}$ Biodiversity Knowledge Integration Center, Arizona State University, Tempe, Arizona, United States \\ Corresponding Author: M. Andrew Johnston \\ Email address: ajohnston@asu.edu
}

The genus Trogloderus LeConte, 1879, which is restricted to dunes and sandy habitats in the western United States, is revised using morphological and molecular information. Six new species are described from desert regions: Trogloderus arcanus New Species (Lahontan Trough); Trogloderus kandai New Species (Owens Valley); Trogloderus major New Species (Mohave Desert); Trogloderus skillmani New Species (eastern Great Basin and Mohave Desert); Trogloderus verpus New Species (eastern Colorado Plateau); and Trogloderus warneri New Species (western Colorado Plateau). A molecular phylogeny is presented for the genus and used to infer its historical biogeography. The most recent common ancestor (MRCA) of Trogloderus is dated to 5.2 mya and is inferred to have inhabited the Colorado Plateau. Current species most likely arose during the midPleistocene where the geographic features of the Lahontan Trough, Bouse Embayment and Kaibab Plateau were significant factors driving speciation. 


\title{
1 Phylogenetic revision of the psammophilic Trogloderus
}

2 LeConte (Coleoptera: Tenebrionidae), with biogeographic

3 implications for the Intermountain Region

4

6

7

8

\author{
M. Andrew Johnston ${ }^{1}$ \\ ${ }^{1}$ Biodiversity Knowledge Integration Center, Arizona State University, Tempe, AZ, USA \\ Corresponding Author: \\ M. Andrew Johnston \\ 734 W. Alameda Dr. Suite 144, Tempe, AZ 85282 USA \\ Email address: ajohnston@asu.edu
}

\begin{abstract}
The genus Trogloderus LeConte, 1879, which is restricted to dunes and sandy habitats in the western United States, is revised using morphological and molecular information. Six new species are described from desert regions: Trogloderus arcanus New Species (Lahontan Trough); Trogloderus kandai New Species (Owens Valley); Trogloderus major New Species (Mohave Desert); Trogloderus skillmani New Species (eastern Great Basin and Mohave Desert); Trogloderus verpus New Species (eastern Colorado Plateau); and Trogloderus warneri New Species (western Colorado Plateau). A molecular phylogeny is presented for the genus and used to infer its historical biogeography. The most recent common ancestor (MRCA) of Trogloderus is dated to 5.2 mya and is inferred to have inhabited the Colorado Plateau. Current species most likely arose during the mid-Pleistocene where the geographic features of the Lahontan Trough, Bouse Embayment and Kaibab Plateau were significant factors driving speciation.
\end{abstract}

\section{Introduction}

The psammophilic genus Trogloderus LeConte, 1879, was originally erected for a unique species and specimen of the family Tenebrionidae (sensu Bouchard et al. 2011, Bousquet et al. 2018). Described as Trogloderus costatus LeConte, 1879, from Rock Creek, Idaho, this heavily sculptured species was thought to be similar to the old-world Scaurini Billberg, 1820, but has long since been associated with the desert stink beetles in the genus Eleodes Eschscholtz, 1829 in what is now considered the tribe Amphidorini LeConte, 1862 (LeConte 1879, Blaisdell 1909, Doyen \& Lawrence 1979, Bousquet et al. 2018). Blaisdell (1909) described a second congeneric species, Trogloderus tuberculatus Blaisdell, 1909, from Los Angeles County, California during his revision of the tribe. A third species, Trogloderus nevadus La Rivers, 1943, was described from the dunes around Pyramid Lake, Nevada (La Rivers 1943). The genus was then revised by La Rivers (1946), where the three previously recognized species were sunk to subspecies of an 
again monotypic genus and a fourth subspecies, Trogloderus costatus vandykei La Rivers, 1946, was described from outside Twentynine Palms, California.

The recognition of subspecies (La Rivers 1946) was supported by invoking the theory of orthogenesis, a teleological view of evolution where species have an internal mutational force that drives them not only to a point of adaptation but then continues to push the species onward towards extinction (Eimer 1898, Mayr 1982; see also Grehan and Ainsworth 1985). Following this reasoning, it was hypothesized that Trogloderus has "embarked on that phase of evolutionary growth which seems to characterize any ancient group in the last stages of its existence - they are developing fluidly and rapidly into grotesque caricatures of their plain and drab ancestors" (La Rivers 1946: 35).

Following the 1946 revision, very little systematic research has been dedicated to this genus; except for two additional subspecies described as Trogloderus costatus pappi Kulzer, 1960, and Trogloderus costatus mayhewi Papp, 1961. All species and subspecies were described from a small number of specimens, with T. nevadus having the largest type series of 14 individuals. Subsequent to the above works, specimens in natural history collections have variously been determined as simply Trogloderus costatus or somewhat haphazardly assigned to subspecies. The last taxonomic changes to the genus were made by this author (MAJ) in the recent catalog of North American Tenebrionidae to stabilize the nomenclature in anticipation of this revision; namely, the subspecific names were all eliminated while restoring $T$. costatus, T. tuberculatus, $T$. nevadus, and $T$. vandykei to specific standing, while $T$. costatus mayhewi $(=T$. vandykei) and $T$. costatus pappi $(=$ T. tuberculatus) were invalidated as junior synonyms (Bousquet et al. 2018).

During the half century since the last taxonomic works were completed, a comparatively large number of Trogloderus specimens have accumulated in North American natural history collections. These, along with targeted fieldwork for molecular vouchers, have made a thorough taxonomic and biogeographic study of Trogloderus possible for the first time.

Trogloderus is distributed throughout the Intermountain Region, which encompasses the generally arid lands of western North America between the Rocky and Sierra Nevada mountains. This region spans the Great Basin and Mojave deserts to the west along with the Colorado Plateau to the east. The most comprehensive biogeographic work on the region was completed by Reveal (1979), based largely on his extensive botanical fieldwork. The vast landscape with limited access, particularly in the state of Nevada, has resulted in a general paucity of distributional knowledge and available specimens of beetles in natural history collections (Will et al. 2017).

The molecular phylogenies inferred for the herein revised species-level entities are used in diversification analyses to infer the age of the genus and constituent species. They are further 
84

91

92

used in historical biogeographic reconstructions to understand the geographic influence of the Intermountain Region during speciation. The biogeographic hypotheses generated from these investigations are discussed in relation to other regional treatments. It is hoped that these insights will spur additional studies within the region and provide a framework to understand the relationships between organisms occurring in sand dunes.

\section{Materials \& Methods}

\section{Morphological methods}

A total of 3,734 specimens were studied. Remarkably, over half $(1,957)$ came from noninstitutionalized collections, which is a testament to the importance of individual collections and collectors for documenting North American darkling beetle diversity. The following collections were used for this study:

\section{ADSC $\quad-$ Aaron D. Smith Collection, Flagstaff, AZ}

AMNH $\quad-$ American Museum of Natural History, New York, NY

ASUHIC $\quad-$ Hasbrouck Insect Collection, Arizona State University, Tempe, AZ

CASC - California Academy of Sciences, San Francisco, CA

CSCA - California State Collection of Arthropods, Sacramento, CA

CIDA - Orma J. Smith Museum of Natural History, College of Idaho, Caldwell, ID

EMEC - Essig Museum of Entomology, University of California, Berkeley, CA

FSCA - Florida State Collection of Arthropods, Gainesville, FL

FWSC - Frederick W. Skillman Collection, Pearce, AZ

KKIC - Kojun Kanda Insect Collection, Flagstaff, AZ

LACM - Natural History Museum of Los Angeles County, Los Angeles, CA

MAJC $\quad-$ M. Andrew Johnston Collection, Tempe, AZ

OSUC - Triplehorn Insect Collection, The Ohio State University, Columbus, OH

RLAC - Rolf L. Aalbu Collection, Sacramento, CA

\section{SWC \\ - Samuel Wells Collection, Cedar City, UT}

UCDC - Bohart Museum of Entomology,University of California, Davis, Davis, CA

USNM - National Museum of Natural History, Washington, DC

WBWC $\quad-$ William B. Warner Collection, Chandler, AZ

Specimens were examined using a Leica MZ16 stereomicroscope fitted with an ocular graticule for measurements. Internal anatomy was studied via 16 whole-body disarticulations where specimens were cleared in warm $10 \% \mathrm{KOH}$, neutralized in $5 \%$ acetic acid, and then separated into constituent sclerotized sections in glycerin. Beetle terminalia were further studied from many more specimens by dry dissection. This technique involved prying abdominal ventrites $4-5$ and associated internal structures from the pinned specimens, soaking them in distilled water, and separating out the sclerotized reproductive structures. These structures (ovipositor or 
118 aedeagus) were then pointed along with the dismembered ventrites and surviving tergites

119 underneath the original pinned specimen.

120

121

122

123

124

125

126

127

128

129

130

131

132

133

134

135

136

137

138

139

140

141

142

143

144

145

146

147

148

149

150

151

152

153

154

155

156

157

Morphological terminology generally follows Doyen (1966). Female terminalia morphology follows Iwan and Kaminski (2016), whereas male terminalia morphology follows Iwan (2001) except for the usage of the term clavae (following Blaisdell 1909) over laciniae for the ventral articulated structures of the fused parameres that flank the penis. A detailed internal and external description is provided for the genus and each species is then accompanied by a smaller differential description for the limited variable characters between species.

The evolutionary species concept of Wiley and Mayden (2000) is employed in this study. Unique combinations of morphological characters, diagnosable monophyletic clades, and coherent geographic distributions were evaluated together to diagnose putative lineages with a shared evolutionary past and unique evolutionary trajectory.

\section{Molecular and biogeographic methods}

A total of 36 specimens of Trogloderus and an additional eight outgroup species from Amphidorini are included in the final matrix. For Trogloderus, all type localities were visited, and specimens representing each described species and subspecies were collected. Specimens were collected from as many known localities as possible, with sampling covering all broadly recognized geographic subregions. The collecting locality of each voucher is shown in Fig. 1, and the voucher numbers are included in all presented phylogenetic trees. An additional eight outgroups were included which span the known generic and subgeneric diversity of Amphidorini (Bousquet et al. 2018).

Fresh specimens were collected and preserved in $95 \%$ ethanol at $-20^{\circ} \mathrm{C}$. DNA extractions were made from either the head capsule or a leg and associated thoracic musculature using the DNEasy Blood \& Tissue Kit (QIAGEN, www.qiagen.com). The six loci amplified via PCR for this study are given in Table 1, PCR cycles and annealing temperatures generally follow Kanda (2017). Forward and reverse sequences were obtained for each PCR product using an Applied Biosystems 3730 DNA Analyzer. The resultant chromatograms were edited for final base calls using GENEIOUS v7 and aligned using MAFFT v7 (Katoh and Standley 2013) as implemented through MESQUITE (Maddison and Maddison 2018). The final aligned dataset contained 3707 base pairs.

All loci were separated into three possible partitions by codon position, except for the ribosomal $12 \mathrm{~s}$ and $28 \mathrm{~s}$ which were each left as a single partition, and were analyzed by PARTITIONFINDER 2 (Lanfear et al. 2016) using unlinked branch lengths and the greedy search algorithm (Lanfear et al. 2012). The resultant two-partition scheme, which consisted of one partition including the third codon position of COI and COII and a second partition containing the rest of the data, was used

Peer] reviewing PDF | (2019:06:38531:1:1:NEW 26 Sep 2019) 
158

159

160

161

162

163

164

165

166

167

168

169

170

171

172

173

174

175

176

177

178

179

180

181

182

183

184

185

186

187

188

189

190

191

192

193

194

195

196

197

in downstream phylogenetic and dating analyses. Phylogenetic reconstruction was performed both by RAXML version 8 (Stamatakis 2014) with support values calculated by rapid bootstrap analysis with 500 replicates, and by MRBAYES v3.2 (Ronquist and Huelsenbeck 2003) which was run using four chains for 10 million generations sampled every 1000 with the first $25 \%$ being discarded as burnin. Trees were rooted by using the clade containing the three Eleodes subgenera Eleodes, Metablapylis Blaisdell, 1909, and Steneleodes Blaisdell 1909 based on previous phylogenetic analyses for the whole tribe (Johnston 2018).

Phylogenetic dating analyses were performed using two methods. First, RelTime (Tamura et al. 2012) as implemented in MEGA7 (Kumar et al. 2016) was used to infer a timetree given the maximum-likelihood (ML) tree from RAxML and the aligned nucleotide data. Second, the BEAST2 package (Bouckaert et al. 2014) was used to infer a dated phylogeny under both a Yule and Birth-Death model. The latter two analyses had unlinked exponential relaxed clocks for each partition and were run for 500 million generations and sampled every 20000 with parameter convergence and estimated sample size being assessed via Tracer 1.7 (Rambaut et al. 2018) and a maximum clade credibility tree being computed by TreeAnnotator from the BEAST2 package with the first $25 \%$ of trees being discarded as burnin.

Two geological calibration points were used for all phylogenetic dating analyses, due to the lack of any fossils for the tribe (Bousquet et al. 2018). The first calibration is the uplift of the Inyo and White Mountains, which form the eastern bounds of the Owens Valley and separate it from the Great Basin and Mojave Desert. The uplift of these mountains started between 2.8 and 2.3 mya (Bachman 1978, Lee et al. 2009), and the calibration prior for the common ancestor of the three Trogloderus species distributed across these mountains was set as a normal distribution with a mean of 2.5 mya and standard deviation of 1 my. The second calibration is the deeply incised eastern margin of the Grand Canyon in northern Arizona. Two populations of a new species were sampled, one from sand dunes north of the Colorado river just below the Vermillion Cliffs, and one south of the Colorado River near Moenkopi. These two populations are separated by the gorge just downstream from Marble Canyon, which was been dated as 0.83 my old (Polyak et al. 2008). The calibration prior for the common ancestor of these two populations was set as a normal distribution with a mean of 0.83 mya and a standard deviation of 0.35 my.

Historical biogeographic reconstructions were performed in the BioGeoBEARS package (Matzke 2013) in R (R Core Team 2018) using the calibrated tree from the RelTime analysis with each species collapsed to a single tip. Six biogeographic regions were defined (Fig. 1) based primarily on previous biogeographic work of the intermountain (Reveal 1979) and southwestern desert (Van Dam and Matzke 2016, Wilson and Pitts 2010) regions. The six areas are as follows: (1) Great Basin - centered around northern Nevada, northwestern Utah and southern Idaho in the regions shaped by the prehistoric lakes Lahontan and Bonneville and including the Snake River plain (Reveal 1979, Britten and Rust 1996, Wilson and Pitts 2010); (2) Mojave Desert - the 
198

199

200

201

202

203

204

205

206

207

208

209

210

211

212

213

214

215

216

217

218

219

220

221

222

223

224

225

226

227

228

229

230

231

232

233

234

235

236

237

southwestern-most region of Trogloderus distribution which includes much of southeastern California, southern Nevada as well as far western Arizona and southwestern Utah (Shreve 1942, Reveal 1979, Wilson and Pitts 2010, Van Dam and Matzke 2016); (3) Lahontan Trough - a transverse transition zone between the Mojave and Great Basin deserts which shares floristic components with both regions and was never part of the prehistoric Lake Lahontan (Reveal 1979, Pavlik 1989, Britten and Rust 1996, Hafner et al. 2006); (4) Colorado Plateau - the desert areas surrounding the four-corners region west of the Rocky Mountains and generally east of the Wasatch mountains of Utah (Reveal 1979, Wilson and Pitts 2010); (5) Owens Valley - a narrow region bounded by the eastern Sierra Nevada mountains to the west and the Inyo and White mountains to the east, this transition region also has strong floral and faunal similarities with both the Mojave and Great Basin deserts (Reveal 1979, Andrews et al. 1979, Macey 1986, Pavlik 1989, Van Dam and Matzke 2016); and (6) Widespread - this was used for outgroup taxa whose ranges do not coincide with the regions listed above and instead extend into other areas of western North America.

\section{Data management and availability}

Label data from all specimens examined were digitized and are available online through the Symbiota Collections of Arthropods Network (SCAN; Gries et al. 2014, http://scan-bugs.org). Collecting events lacking GPS data on the label were georeferenced using Google Earth Pro version 7.3 and GEOLocate (www.geo-locate.org) as implemented in SCAN. Specimens from external institutions, which constituted the majority of those examined, were digitized using the SCAN Collection of Externally Processed Specimens (ARTSYS, see Johnston et al. 2018). All molecular and disarticulation vouchers are deposited in the MAJC and have images available with the pertinent specimen records on SCAN. Due to the fully digitized and available specimen data, verbatim label data are not included in the main text except for holotypes. Georeferenced specimen records were mapped using QGIS v3.2 which incorporated Google Earth satellite imagery.

Full locality, institutional ownership, determination, and georeferencing data for all specimens studied are available as a csv file in Supplemental Data S1. A Darwin-Core Archive of all digitized specimen data is available in Supplemental Data S2. Full sequence alignments and configuration files for divergence analyses are available in Supplemental Data S3. Individual sequences are also deposited on GenBank with accession numbers: [NOTE: Will submit to GenBank upon manuscript acceptance].

The electronic version of this article in Portable Document Format (PDF) will represent a published work according to the International Commission on Zoological Nomenclature (ICZN, ICZN 1999, ICZN 2012), and hence the new names contained in the electronic version are effectively published under that Code from the electronic edition alone. This published work and the nomenclatural acts it contains have been registered in ZooBank, the online registration 
238

239

240

241

242

243

244

245

246

247

248

249

250

251

252

253

254

255

256

257

258

259

260

261

262

263

264

265

266

267

268

269

270

271

272

273

274

275

276

system for the ICZN. The ZooBank LSIDs (Life Science Identifiers) can be resolved and the associated information viewed through any standard web browser by appending the LSID to the prefix http://zoobank.org/. The LSID for this publication is:

urn:1sid:zoobank.org:pub:678EBFE3-6308-4FB8-8E93-184CEC9A15E7. The online version of this work is archived and available from the following digital repositories: PeerJ, PubMed Central and CLOCKSS.

\section{Systematics}

\section{Amphidorini LeConte, 1862}

The complex nomenclatural and taxonomic history of Amphidorini has been summarized by Doyen and Lawrence (1979) and Johnston et al. (2015), and is only briefly described here. The tribe has frequently and historically been treated within the subfamily Tenebrioninae Latreille, 1802 (Bouchard et al. 2005, 2011; Bousquet et al. 2018), but recent phylogenetic studies place the Amphidorini in a clade with several other tribes in what has been referred to as the subfamily Opatrinae Brullé, 1832 (Aalbu et al. 2002, Kanda 2017, Kaminski et al. 2018).

The North American genera of this tribe can be separated from other members of Tenebrionidae by the following combination of characters: abdominal ventrites III-IV with visible membrane along hind margin; antennae lacking compound stellate sensoria; tarsal claws simple, not pectinate; penultimate tarsomeres not lobed beneath; elytra fused medially, hind wings reduced to small folds; paired defensive glands present between abdominal sternites VII and VIII, glands separate lacking a common volume, glands smooth, not annulated; mentum trilobed with mesal face more or less produced anterad, often concealing insertion of ligula; female paraproct and coxite short, coxite 1-segmented, with short subapical gonostyle; female with single, bursaderived spermatheca.

The tribe is currently comprised of seven genera, six of which are known only from North America. Published keys to genera (Aalbu et al. 2002, Johnston et al. 2015) are sufficient to separate Trogloderus from other Amphidorini, though a generic revision of the tribe is in progress (Johnston and Smith in prep).

\section{Trogloderus LeConte, 1879}

Type species Trogloderus costatus LeConte, 1879, by monotypy

Diagnosis. Trogloderus (Fig. 2) can be distinguished from other members of Amphidorini by the following characters: body roughly sculptured, pronotum either tuberculate or roughly punctured. Elytron with four sharply carinate longitudinal costae, elytral suture costate or not. 
277 Tarsi lined beneath with yellow to castaneus spicules, never with tomentose pads, probasitarsus 278 thickened ventrally near distal margin.

279

280 Male: Body elongate, roughly sculptured, ferruginous to black. Length 9-16 mm. Width 4-6 $281 \mathrm{~mm}$.

282 Head. As broad as long. Antenna 11-segmented, extending to posterior 2/3 of pronotum; 283 antennomere III $1.5 \times$ as long as IV, IV-VII obconical, roughly as long as wide, VIII-XI wider 284 than long, VIII with sensory patch of yellow setae along outer margin of apical face, IX-XI with 285 sensory patch forming continuous ring around apical face. Labrum free, partially exposed, 286 broader than long; anterior margin rounded laterally, deeply sinuate mesally; each lobe bearing 287 tuft of short yellowish setae; dorsal surface punctate, each puncture bearing a long yellow seta, 288 punctures becoming denser anteriorly; hypopharynx originating just posteriorly of anterior 289 290 ventral margin, anterior hypopharyngeal sclerite ovoid, transverse, $1.5 \times$ wide as long. Mandibles (Fig. 3A-B) roughly symmetrical, bidentate, the left slightly larger than and overlapping the right at rest; dorsal face striate, more strongly so anterolaterally; lateral face with longitudinally elongate punctures, each bearing a single seta; ventral surface concave, smooth; mola present, strongly sclerotized, finely granulate; prostheca large, membranous, extends laterally around mola to form a large submola. Maxillae (Fig. 3C-D) ferruginous, symmetrical; cardo subtriangular, narrowing proximaly, lightly punctate; basistipes bearing thickened setae, subtriangular, narrowing distally, articulated with cardo basally and basigaleaanterolaterally, mediostipes anteromesolly, and palpifer anterolaterally; mediostipes subtransverse, glabrous, articulated with lacinia distally; lacinia well developed, mesal surface bearing a terminal digitus followed proximally by robust lacinial teeth which become setae in basal $1 / 3$; basigalea thin, articulated with distigalea apically, bearing fine, long setae; distigalea $1.5 \times$ longer than wide, anterior and mesal surface densely clothed with thick yellowish setae, dorsal surface bearing moderately separated, long yellowish setae; palpifer digitate ventrally, bearing stout setae; palpi with 4 palpomeres, palpomere I small, subtriangular, II elongate, obconical, III slightly shorter than II, clavate, IV securiform, apical surface bearing yellowish membranous sensorium. Mentum (Fig. 3E) trilobed, with mesal region of dorsal face produced anteriorly into arcuate lobe, covering insertion of ligula; ligula transverse, bearing two apical tufts of stout setae along dorsal face; labial palp with 3 palpomeres, palpomere I obconical, as long as wide, II clavate, $1.5 \times$ long as wide, III fusiform and evenly setose; hypopharyx moderately sclerotized along anterior margin, hypopharyngeal brush forming thickened longitudinal band from anterior margin of hypopharynx to posterior margin of mentum. Clypeus fused to frons, roughly sculptured, broadly sinute at middle, frontoclypeal suture indistinct to faintly traceable in teneral individuals. Frons usually slightly sunken, less roughly sculptured than clypeus, with slightly elevated bilobed tubercle centrally; epistomal lobes produced, distinctly offset from clypeus. Eyes entire, reniform, dorsal lobe 5-6 facets wide, ventral lobe 3 facets wide. Vertex at same level and contiguous with central tubercle of frons; becoming strongly granulate towards occiput. 
316 Submentum short, arcuate posteriorly, faintly evident; gular sutures diverging posteriorly, well

317 rounded, gula less coarsely sculptured than surrounding head capsule.

318

319 Thorax. Pronotum roughly sculptured; lateral margins strongly curved, crenulate along entire

320 length, sinuate at posterior angle, anterior angles acute, projected, with longitudinal depression

321 along midline, often separated into anterior and posterior foveae (Fig. 2A, pf); prosternal length

322 from anterior margin to procoxae subequal to procoxal diameter; procoxae separated by

323 approximately $1 / 2$ procoxal diameter; prosternal process (Fig. $2 \mathrm{~B}, \mathrm{pp}$ ) projected posteriorly;

324 procoxal cavities closed posteriorly by postcoxal bridge of pronotum which meets the prosternal

325 process mesally; pleural apophysis (Fig. 4A) directed anterodorsally, becoming laminar and

326 longitudinally expanded near ventral surface of pronotum, with short dorsal coxal articulation

327 extended mesally around basal 1/3; prosternal apophysis straight, extending dorsolaterally,

328 terminating near dorsal margin of coxa. Mesonotum strongly transverse, triangular, densely

329 papillose; scutellar shield wide and short, lacks papillae, strongly microsculptured;

330 mesanepisternum subtriangular, narrowing posteroventrally, anterior $1 / 3$ with integument

331 thickened, papillose, offset from posterior $2 / 3$ by posteriorly concave ridge demarking a section

332 of thinner integument, punctate in posterior 1/3; mesepimeron short, fairly evenly punctate;

333 mesoventrite with anterior $1 / 2$ covered by prothorax at rest, posterior $1 / 2$ projected ventrally

334 between coxae, with longitudinal groove to receive prosternal process; mesocoxal cavities closed

335 externally by mesoventrite, mesepimeron, and metaventrite; mesosternal apophyses extend

336 anteriorly from apex of mesocoxal cavity, recurved dorsally and then posteriorly around anterior

337 1/4 of mesoventrite. Metanotum greatly reduced, prescutum forming narrow arch, strongly

338 connected to the mesonotum, remainder of metanotum forming short, somewhat heavily

339 sclerotized membrane, without discernable subregions; metepimeron forming narrow rod-like

340 longitudinal sclerite along length of metathorax, concealed beneath elytron, posteriorly with

341 short ventrally projected metepimeral process which is fused with metepisternum above

342 metacoxal cavity; metepisternum elongate, subrectangular; metaventrite short, length less than

343 mesocoxal diameter, antecoxal ridge deeply impressed above anterior coxal margin, discrimen

344 not apparent; metacoxal cavities closed externally by metaventrite, metepisternum, metepimeral

345 process, and first abdominal ventrite; metendosternite (Fig. 4A) stout, stalk broad, ventral

346 longitudinal flange very well sclerotized, furcae as wide as stalk, relatively immovable, furcal

347 apicies reflexed posterolaterally, forming horizontal pad for furca-trochanteralis muscle

348 attachment, anterior tendons inserted at apical 1/4 of furcae. Elytra fused, suture elevated or not;

349 elytron disc (Fig. 2A, dc) with 4 longitudinal carinate costae; epipleuron narrow throughout

350 length, not or slightly widened anteriorly, attaining elytral apex posteriorly. Hind wings greatly

351 reduced, forming veinless tubular sac, approximately the size of first abdominal spiracle.

352

353 Legs. Fore leg slightly enlarged, weakly fossorial; femur clavate, heavily punctate, dorsal

354 anterior margin carinate from base to apical 1/5, ending in short recurved spine (Fig. 2A, $f s$ );

355 tibia with inner face excavated in basal $1 / 5$, outer face carinate from base to near tarsal insertion, 
356

357

358

359

360

361

362

363

364

365

366

367

368

369

370

371

372

373

374

375

376

377

378

379

380

381

382

383

384

385

386

387

388

389

390

391

392

393

394

395

apex bearing row of ferruginous spicules dorsally, tibial spurs subequal, extending to apex of tarsomere II; tarsus bearing furriginous spicules, tarsomere I ventrally thickened at apex, maximum height equal to length, II-IV subequal, relatively short, about as tall as long, V slightly clavate, as long as II-IV combined; empodium minute, hidden within tarsal apex, bearing 2 yellowish setae; tarsal claws simple, evenly arcuate, $2 / 3$ length of tarsomere V. Middle and hind legs similar to fore leg, tibia subcylindrical, not expanded; all tarsomeres simple, not thickened beneath.

Abdomen. 5 visible ventrites, ventrite I intercoxal process truncate, rectangular, twice as broad as long, I-III connate, fused to elytra laterally, III-IV with visible membrane posteriorly, I-II bearing variously developed longitudinal ridges demarking flattened abdominal depression (Fig. $2 \mathrm{~B}$, ad) in line with thoracic intercoxal region; tergites membranous, weakly sclerotized; paired defensive glands (Fig. 4B) present posterior to ventrite V (between sternites VII-VIII), glands lacking a common volume, each gland elongate, subfusiforme, extending anterior of ventrite II, membrane finely strigose, lacking annular pleats, gland openings centered around lateral 1/5.

Terminalia. Tergite VIII weakly sclerotized, posterior margin evenly arcuate, bearing row of fine golden setae; sternite VIII weakly sclerotized, bilobed, deeply emarginate posteriorly, each lobe subtriangular, clothed ventrally and posteriorly with long yellowish setae, anterior deeply margin bisinuate, thickened into apodemes. Spicules V-shaped, fused anteriorly, $1.5 \times$ length of tergite VIII, spicule plates moderately small, $4 \mathrm{x}$ width of spicules, twice as long as wide. Adeagus (Fig. 5C) elongate, cylindrical; basal piece $4 \mathrm{x}$ as long as wide, lateral margins (alae) reflexed inwardly, leaving ventral face open, apicodorsal margin concave; parameres fused, $1 / 2$ length of basal piece, widest basally, $1.5 \mathrm{x}$ long as wide, apical half curved ventrally; clavae (Fig. 5C) narrow, about as long as parameres, 1/6 maximum width of parameres; penis narrow, lightly sclerotized, fully hidden dorsally by parameres at rest.

Female. As male but generally stouter, fore femoral spines variable, typically less developed than those of males, base of tibia generally not constricted, central abdominal groove less developed.

Terminalia. Tergite VIII moderately sclerotized, posterior margin evenly arcuate, bearing golden setae; sternite VIII moderately sclerotized, evenly arcuate podsteriorly, bearing golden setae, fused medially to spiculum ventrale along anterior margin, spiculum ventrale $1.5 \times$ medial length of tergite VIII. Proctiger (Fig. 5A) slightly longer than wide, posterior margin weakly emarginate, bearing single row of short yellow setae. Paraproct subrectangular dorsally (Fig. 5A), subtriangular ventrally (Fig. 5B), bacculus obliquely pointed psoteromesally, thickened mesally. Coxite 1-segmented, subrectangular in dorsal view, narrowing posteriorly, subtriangular in ventral view, bacculus obliquely pointed anteromesally. Gonostyle short, inserted ventrally, at most weakly visible from above. Bursa copulatrix (Fig. 5B) about $2 \times$ length of coxite, bearing 
396

397

398

399

400

401

402

403

404

405

406

407

408

409

410

411

412

413

414

415

416

417

418

419

420

421

422

423

424

425

426

427

428

429

430

431

432

433

434

single spermatheca (Fig. 5A) off of duct from anterior margin with single long spermathecal gland.

\section{Variation and natural history}

Sexual dimorphism is primarily observed in the fore tibiae and abdominal ventrites. The fore tibiae of males are generally more explanate along the outer edge and are more strongly constricted proximally. The femoral spines are often slightly stronger in the males as well, where they pair with the constricted tibiae to form a grasping mechanism - presumably used to hold the females legs or antennae during copulation. The abdominal depression also tends to be stronger in males, with the marginal ridge more produced and the central region more depressed. This is also assumed to help the male in positioning during copulation.

Relatively little is known of Trogloderus biology. Adults have not been successfully cultured in the lab and larvae and pupae remain unknown and undescribed from the wild. Adult beetles are able to burrow into loose sand, where the immature stages presumably live. More commonly, adults are observed emerging from mammal burrows after dark where they seem to take shelter underground during the day. Like other Amphidorini, adults can also be found, though not particularly abundantly, under rocks or loose boards. Trogloderus are very active at night, and seem to travel good distances across open ground likely in search of food, mates, or new sites to shelter during the day.

Collection records and field observations indicate that this genus is restricted to habitats with loose sand. While the largest populations seem to be from deep aeolian sand formations, they can also be found in areas of fine loose sand along rivers and across desert flats, e.g., in small sand hummocks around the base of desert shrubs.

\section{Key to the species of Trogloderus}

Diagnostic utility of characters

The extreme sculpturing of Trogloderus makes the genus readily recognizable among Amphidorini, but also seems to magnify - in the context of species identification - the relatively broad individual and geographic intraspecific variation found throughout the tribe (e.g., see Triplehorn and Thomas 2012; Johnston 2015, 2016). The female ovipositor has been heavily relied upon to classify species into genera and subgenera (Blaisdell 1909; Triplehorn and Thomas 2012; Johnston 2015, 2016), yet it is fairly constant throughout Trogloderus and was found unreliable for species identification. Male terminalia can be diagnostic for some species, but not for all (Somerby 1972, Aalbu et al. 2012). Within Trogloderus, the basic shape of the parameres can sometimes aid in distinguishing some species from each other by examining the curvature of the lateral margins, but do not alone reliably distinguish one species from all others. 
435 General facies, elytral sculpturing, and body size were found to be largely unreliable for species 436 recognition as they can vary within populations and especially between populations. It is not 437 uncommon to find locally homogenous populations to have strong differences between them. 438 Whether this is due to some environmental variable such as food or water availability or simply 439 stochastic due to limited gene flow is unclear. The sculpturing of the pronotum and head seems 440 to be more stable within species and are heavily relied upon in the following identification key.

441

442 Though coloration was previously used as a secondary diagnostic character (La Rivers 1946, 443 Papp 1961), it is here found to be unusable for species determinations. Rather, it seems that the 444 cuticle of adult Trogloderus takes a fairly long time to fully harden and that more teneral 445

446

447

448

449

450

451

452

453

454

455

456

457

458

459

460

461

462

463

464

465

466

467

468

$469 \quad 3$ '

470

471

472

473

474

specimens exhibit a red coloration, which then matures to a darker black in the longest-lived individuals. This is based on the observation that in almost every large series known there is a spectrum of red to castaneus to black individuals. Specimens with a brighter red coloration seem to have thinner cuticle (personal observation while pinning specimens) and even less strongly sclerotized terminalia. This is perhaps a strategy for these desert-dwelling beetles to limit the duration of the potentially more susceptible immature stages in preference of a longer hardening period as an adult. It is not clear whether the teneral adults are reproductively viable as no eggs have been observed in such individuals when dissected, and this could be an example of Reifungsfraß, the need for a maturation feeding period (see McNee et al. 2000).

\section{Dichotomous key to the species of adult Trogloderus}

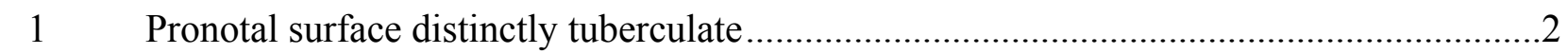

1' Pronotal surface not tuberculate, heavily punctate to cribrate ............................................

2 (1) Each elytron with large subapical tubercle at outer carinal terminus; pronotal foveae delimited laterally by raised longitudinal ridges (Mojave Desert)

..Trogloderus tuberculatus Blaisdell (Fig. 6A)

2' Elytra without posterior tubercles; pronotum lacking elevated ridges, foveae lined by tubercles originating from same surface as those of the disc (widespread)..........................

3 (2') Posterior pronotal angles more or less inflated; lateral margins of pronotal disc slightly depressed, lacking tubercles (western Colorado Plateau). Trogloderus warneri n. sp. (Fig. 6C)

3. Posterior pronotal angles not at all inflated; lateral regions of pronotal disc not depressed, tubercles relatively evenly dispersed from foveae to lateral margins

4 (3') Male parameres triangular, evenly tapering from base to apex; elytral carinae often granulately tuberculate on sides (west of Kaibab Plateau)... Trogloderus skillmani n. sp. (Fig. 6D) 
475 4' Male parameres distinctly constricted near base, then evenly tapering to apex; elytral

476

477 carinae usually lacking tubercles on sides (east of Kaibab Plateau)

478

479

5 (1') Pronotal dorsum bilobed in anterior view; pronotum strongly explanate laterally; pronotal

480

481 foveae joined into single longitudinal groove (Mojave Desert)

482 Trogloderus vandykei La Rivers (Fig. 1)

483

484

485

$6\left(5^{\prime}\right)$ Pronotum cribrately punctured, margins of punctures strongly elevated; intervals between

486

487

488

Pronotum evenly convex in anterior view; pronotum weakly to moderately explanate laterally; pronotal foveae variable, often distinctly separated (widespread)

7 (6') Propleurae lacking tubercles on dorsal half, never with tubercles anteriorly just underneath pronotal margin; pronotal foveae joined into single well-demarked

493 longitudinal groove Trogloderus major n. sp. (Fig. 6H)

7. Propleurae wth tubercles in dorsal half, at least anteriorly underneath pronotal margin;

495

496

497

498 pronotal foveae variable, usually not forming single longitudinal groove

8 (7') Epistoma roughly punctured, individual punctures evident above antennal insertion; pronotal punctures fairly evenly circular, discrete; elytral costae moderately to strongly produced; male parameres broadly triangular in dorsal view, sides straight and evenly

500 tapered (southern Owens Valley)

501

Trogloderus kandai n. sp. (Fig. 6I)

503

504

505

506

507

9 (8') Frontoclypeal suture forming a complete transverse ridge, frons apex below the plane of

508

509

510

511

512 9'

513

514

Trogloderus nevadus La Rivers (Fig. 6G) clypeus base; male parameres broadly triangular, evenly converging; prosternal process horizontal, on the same plane as the prosternum between the procoxae; punctures larger (northern Great Basin)

9' Frontoclypeal suture usually not forming complete transverse ridge, mesal region of frons apex on the same plane as clypeus; male parameres usually noticeably constricted near base, with sides slightly convexly arcuate; prosternal process often narrowed at posterior 
515

516

517

518

519

520

521

522

523

524

525

526

527

528

529

530

531

532

533

534

535

536

537

538

539

540

541

542

543

544

545

546

547

548

549

550

551

552

553

554 procoxal margin, sometimes dorsally offset from plane of prosternum; pronotal punctures usually smaller (Lahontan Trough including Mono Lake region of Owens Valley)

Trogloderus arcanus n. sp. (Fig. 6E)

\section{Trogloderus arcanus Johnston, New Species}

urn:lsid:zoobank.org:act:0BCDA9E8-F615-41B9-9376-62778B0958EE

Figures $6 \mathrm{E}, 7 \mathrm{~A}, 8$

Diagnosis. Trogloderus arcanus can be distinguished from all congeners, except $T$. nevadus, by the combination of tuberculate propleurae, frons, and clypeus. To separate it from the latter, the characters given in the key will usually separate the two species, but see the variation and remarks below.

Description. As genus with the following: Length $7.0-10.5 \mathrm{~mm}$, width $3.5-4.5 \mathrm{~mm}$. Head. Epistoma and frons tuberculate, lacking distinct punctures; mesal region of frons elevated, usually on same plane as clypeus, rendering transverse ridge along frontoclypeal suture incomplete, lateral regions of frons usually evenly tuberculate. Thorax. Pronotum evenly convex dorsally; heavily punctate, punctures longitudinally elongate, tending to coalesce anteriorly; lateral margins moderately arcuate, sinuate along basal fifth; posterior pronotal angles obliquely acute, relatively small; anterior fovea usually obsolete to moderately impressed, posterior fovea always distinct, round, deeper than anterior. Propleurae usually tuberculate throughout, tubercles always present anteriorly underneath pronotal margin. Prosternal process usually narrowed along posterior procoxal margin, often narrowed and on slightly dorsal plane than prosternum between procoxae. Elytral costae weakly to moderately developed, intervals usually smooth, occasionally with slight transverse ridges; elytral suture elevated along poster half, nearly as prominent as discal costae. Abdomen. Abdominal depression relatively weak, usually not discernable on ventrite II. Male terminalia. Parameres (Fig. 7A) usually appearing narrow, arcuately constricted near base, sides usually slightly concave, occasionally appearing roughly evenly triangular.

Variation. The diagnostic characters of this species are quite variable both within and between populations. Specimens from Crescent Dunes south to Sarcobatus Flats tend to have a distinctly narrowed prosternal process, while specimens from Teel's Marsh and Silver Peak west to Mono Lake tend to have a horizontal, evenly narrowing prosternal process. Specimens from lower elevation regions (typically Nevada) are fairly weakly sculptured, having rather small pronotal punctures, sometimes becoming separated by as much as half of their diameter, and fairly weakly developed elytral costae. Specimens from higher elevation (e.g., Mono County, CA) tend to be more roughly sculptured on the pronotum and elytra. The latter populations tend to also have the frontoclypeal ridge more or less complete throughout. The northern and eastern populations (e.g., Crescent Dunes and Coal Valley) have more distinctly narrowed parameres, while the southern populations (e.g., Silver Peak) tend to have slightly broader and more evenly tapered parameres. 
555

556

557

558

559

560

561

562

563

564

565

566

567

568

569

570

571

572

573

574

575

576

577

578

579

580

581

582

583

584

585

586

587

588

589

590

591

592

593

594

Distribution. Fig. 8. This species is distributed throughout the region known as the Lahontan Trough (Reveal 1979), a region which was never part of the prehistoric Lake Lahontan to the north.

Type material. Holotype. "USA: NEV: Nye Co., 12 mi / NW Tonopah, Crescent / Dunes; 38¹3'47’N, 117 / 20'06”W; JUN 30-JUL 9 / 2011; barrier pitfalls w. / fish bait; W.B. Warner", "ARTSYS0007057” bearing red holotype label. Deposited in ASUHIC, catalog number ASUHIC0101562. Paratypes. 765 specimens from throughout the range bearing blue paratype labels (see Supplemental Data S1, Supplemental Data S2 or SCAN for full specimen data).

Etymology. The specific epithet, meaning secret, or mysterious (Brown 1956), is given for this cryptic species that was very difficult to separate from $T$. nevadus and was first revealed as a distinct species through the molecular phylogeny presented below.

Remarks. The geographically linked morphological variation in this species warrants further study, which will rely on increased collecting efforts in an under-collected region and likely more molecular data. The slightly heterotypic species as circumscribed here may represent a cryptic species complex. Strong differences between populations may be the result of reproductive isolation and diverging evolutionary lineages, or could be linked to environmental conditions. The roughly sculptured populations from California are from cooler and more mesic habitats, whereas the central Nevada populations face much drier and warmer conditions. There also may be some competitive exclusion or prezygotic isolation pressures, which shape the Nevada populations that border along the range of T. nevadus.

\section{Trogloderus costatus LeConte, 1879}

Figures $6 \mathrm{~F}, 7 \mathrm{~B}, 8$

Diagnosis. Trogloderus costatus can be easily separated from all congeners by the cribrately punctate pronotum, where the margins of the punctures are strongly elevated. The presence of transverse ridges in the intervals of the elytral costae can also separate this species from any others with punctate pronota.

Redescription. Length 10.5-12mm, width 4-4.75mm. Head. Epistoma and frons roughly punctured to tuberculate; frontal tubercle usually roughly punctured, punctures usually becoming discrete tubercles towards clypeus; frontoclypeal suture forming gentle, complete transverse ridge. Thorax. Pronotum relatively evenly convex dorsally; cribrately punctured, punctured region elevated above less punctate lateral margins; anterior and posterior foveae very distinct, deep, impunctate; lateral margins evenly arcuate, recurved just before posterior angles; posterior 
595 angles obliquely acute, small. Propleurae distinctly and evenly tuberculate throughout. Prosternal 596 process horizontal, forming short, evenly tapered triangle behind posterior procoxal margin.

597 Elytral costae strongly developed, intervals always with distinct transverse ridges; elytral suture 598 strongly elevated, nearly as prominent as discal coxae along posterior 5/6. Abdominal depression 599 weak, not evident in females, occasionally evident on anterior $1 / 2$ of ventrite I in males. Male 600 terminalia. Parameres (Fig. 7B) narrow, arcuately constricted near base, sides concave, weakly 601 arcuately converging to apex.

602

603 Variation. As with most other species, the intensity of the body sculpturing is variable both 604 between and within populations. Specimens from near Winnemucca tend to have the weakest 605 sculpturing, though the strongly elevated punctate regions of the pronotum are still diagnostic.

606 Trogloderus costatus has the most variable cephalic sculpturing within the genus, with 607 specimens ranging from having the entire dorsal aspect of the head distinctly punctate (Truckee 608 river near Reno) to specimens that possess nearly entirely tuberculate heads (Winnemucca).

609 Specimens from other regions have a mixture of both, generally with the frontal tubercle

610 punctate and the punctures becoming distinct tubercles towards the clypeus.

611

612 Types. Holotype male from Rock Creek Owyhee County, Idaho at the Museum of Comparative 613 Zoology, type number 4624, pictures available on-line from MCZ type specimen database.

614 LeConte (1879: 3) specifically references "one specimen kindly given me by Mr. Reinecke;

615 others are in the collections of Dr. Horn and Mr. Bolter." This statement is here interpreted to 616 comply with the International Code of Zoological Nomenclature (1999) Article 73.1.1 and the

617 above single specimen is considered the holotype upon which the nominal species was founded, 618 with the secondarily mentioned specimens considered as paratypes.

619

Material examined. 63 specimens (see Supplemental Data S1, Supplemental Data S2 or SCAN for full specimen data).

622

623 Distribution. Fig. 8. This species is known from the Northern Great Basin, from regions once 624 dominated by the prehistoric Lake Lahontan through the Snake River Plain.

625

626 Remarks. This is the second least abundant species found in natural history collections, yet was 627 the first species described in the genus. While true T. costatus, as recircumscribed here, is 628 uncommon in collections, most existing specimens are determined to this species likely 629 following the treatment of La Rivers (1946). Trogloderus costatus overlaps most of the range of $630 T$. nevadus, though the latter is much more frequently collected. Specimens of T. costatus seem 631 to retain the most substrate on their cuticle among all of its congeners, and perhaps this cryptic 632 lifestyle makes it less commonly collected, or perhaps this morphological sculpturing is adapted 633 to more specific substrates. With relatively few specimens known, and many of them lacking 
634 very precise locality data, increased collecting efforts may help elucidate drivers of this species' 635 distribution and intense morphological sculpturing.

636

637

638

639

640

641

642

643

644

645

646

647

648

649

650

651

652

653

654

655

656

657

658

659

660

661

662

663

664

665

666

667

668

669

670

671

672

\section{Trogloderus kandai Johnston, New Species}

urn:1sid:zoobank.org:act:09FCBD7E-3DE8-40E4-8C13-5EC6DFA734EA

Figures 6I, 7C, 8

Diagnosis. Trogloderus kandai can be separated from its congeners by having the pronotum punctate, propleurae tuberculate, and the epistoma distinctly punctured, at least above the antennal insertions. Most similar to T. arcanus, particularly specimens from the Mono Lake region, T. kandai can be further separated from the latter by the pronotal punctures being nearly evenly round and not tending to coalesce (longitudinally oval and tending to coalesce anteriorly in T. arcanus).

Description. Length 9-11 mm, width 3.5-4.5mm. Head. Epistoma aspirately punctate, distinctly so above antennal insertions, often becoming somewhat tuberculate mesally; frontoclypeal suture forming complete transverse ridge; frons irregularly tuberculate, frontal tubercle fairly distinctly punctate, lobes connected by anterior transverse ridge. Thorax. Evenly convex dorsally; heavily and evenly punctate throughout, punctures round, not becoming coalescent, occasionally slightly elongate near anterior margin; lateral margins evenly arcuate, recurved just before posterior angles; posterior angles obliquely acute, small; anterior fovea usually forming moderately and evenly impressed longitudinal channel connected to posterior fovea, posterior fovea round, deeper than anterior fovea. Propleurae tuberculate, tubercles often obscure posteriorly, always with tubercles anteriorly underneath pronotal margin. Prosternal process horizontal, forming evenly tapered triangle behind posterior procoxal margin. Elytral costae moderately produced, intervals punctate but lacking well developed transverse ridges; elytral suture usually not elevated basally, somewhat elevated in posterior $1 / 2$ but less produced than discal costae. Abdomen. Abdominal depression moderately developed in both sexes, distinctly present on ventrites I-II, smoother than lateral region of ventrite in males, entire ventrite fairly similarly sculptured in females. Male Terminalia. Parameres (Fig. 7C) somewhat broad, evenly tapering from base to apex.

Variation. This species exhibits relatively constant morphology, perhaps due to the extremely limited known distribution. The sculpturing of the epistoma can be fairly variable within the population, but individual punctures can be observed along the outer edge above the antennal insertion. The elytral suture is also somewhat variable, usually being elevated in the posterior half, it is occasionally elevated along most of its length.

Peer) reviewing PDF | (2019:06:38531:1:1:NEW 26 Sep 2019) 
673 Distribution. Fig. 8. This is the most geographically restricted species of Trogloderus and is 674 known only from the southern Owens Valley in California, in the region around Owens Lake 675 between independence and Olancha.

676

677 Type material. Holotype. "USA:CA:Inyo Co. / Olancha Dunes OHV area / N36 17.665'

678 W11759.191'/ 3600 ft. KK07_028 / K. Kanda, 22.vii.2007”, “ARTSYS0007058” bearing red

679 holotype label. Deposited in the ASUHIC, catalog number ASUHIC0101561 Paratypes. 82

680 specimens bearing blue paratype labels (see Supplemental Data S1, Supplemental Data S2 or

681 SCAN for full specimen data)

682

683

Etymology. I am pleased to name this species after the tenebrionid specialist Kojun Kanda, who

684 both collected the holotype and provided direction on the molecular analyses.

685

686

Remarks. The restricted distribution of this species is very interesting, being bounded by the

687 Coso Range to the south and a series of old lava flows to the north which are part of the southern

688 boundary for the Tinemaha Reservoir. South of the Coso Range is traditional Mojave Desert

689 habitat and is dominated by creosote bush (Larrea tridentata (DC.) Coville) which is only

690 sporadically present to the north, largely replaced by the Great basin indicative big sagebrush

691 (Artemisia tridentata Nutt.). Thus, $T$. kandai is only known from a transition region between the 692 Mojave and Great Basin deserts.

693

\section{Trogloderus major Johnston, New Species}

695 urn:lsid:zoobank.org:act:1B61B89E-5839-47CA-AA20-F4795FF931D7

696 Figures $6 \mathrm{H}, 7 \mathrm{D}, 9$

697

698

699

Diagnosis. This species can be recognized by having a punctate and evenly convex pronotum,

700 and the propleurae lacking tubercles on the dorsal half (if propleural tubercles present, they are

701 located on the bulging region covering the procoxae). This species can be further separated from most other species with punctate pronota by the smooth elytral suture, located in a depressed

702 interval between the inner elytral costae. This form of the elytral suture and propleurae lacking

703

704 tubercles is shared with the sympatric species $T$. vandykei, which has a bilobed dorsum of the

705

706 pronotum in anterior view.

707

Description. As genus with the following: Length $9.5-13.5 \mathrm{~mm}$, width $4-5.5 \mathrm{~mm}$. Head.

708 Epistoma usually distinctly punctured, sometimes becoming irregularly tuberculate mesally; frontoclypeal suture forming complete transverse ridge; frontal tubercle punctate, lateral regions

709 of frons smooth. Thorax. Pronotum evenly convex dorsally; heavily and evenly punctate

710 throughout; lateral margins fairly evenly arcuate, recurved just before posterior angles; posterior

711 angles obliquely acute, very small; anterior fovea forming weakly to moderately impressed

712 longitudinal channel, connecting to posterior fovea; posterior fovea round, moderately 
713 impressed, slightly deeper than anterior fovea. Propleurae lacking punctures on dorsal half,

714 always lacking punctures anteriorly underneath pronotal margin, usually with indistinct tubercles

715 on inflated region covering procoxal cavity. Prosternal process robust, horizontal, forming

716 evenly tapered triangle behind procoxal posterior margin. Elytral costae weakly to moderately

717 elevated, intervals relatively smooth, bearing faint traces of transverse ridges; elytral usually

718 suture not elevated, or if elevated posteriorly then significantly shorter than the discal costae.

719 Abdomen. Ventrites relatively smooth laterally; abdominal depression strong, distinct in both

720 sexes, stronger in males, margins of depression roughly punctured, depression distinctly

721 margined throughout ventrites I-II; ventrite III flattened anteriorly in males, lacking a distinct

722 margin. Male Terminalia. Parameres (Fig. 7D) subparallel in basal 1/5, then concave and

723 arcuately tapering to apex.

724

725 Variation. This species is fairly constant in its robust form. The main variation observed was in

726 the elytral suture, which is usually entirely not elevated, but is occasionally produced in the

727 posterior half, though is still very much shorter than the discal costae.

728

729

730

Distribution. Fig. 9. Mojave Desert, from Edwards and Ridgecrest California, east through

731

Mercury and Alamo, Nevada. This species is particularly abundant from sand dunes in the

732

733 eastern Mojave and Death Valley (e.g., Kelso, Eureka, and Big Dune).

Type material. Holotype. "USA:CA: San Brndno / Co., Kelso Dunes; 34 / 53'23”N, 11543'04”W / April 16-17. 2011; at / night gleaning \& UV / lights; W.B. Warner”, "ARTSYS0007056", bearing red holotype label. Deposited in the ASUHIC, catalog number ASUHIC0101564. Paratypes. 724 specimens from across its range, bearing blue paratype labels.

738 (see Supplemental Data S1, Supplemental Data S2 or SCAN for full specimen data).

740

Etymology. This species is named for its robust stature (Brown 1956) among Trogloderus.

742

Remarks. This species can often be recognized by gestalt, owing to its generally robust outline

743 with a fusiform abdomen. One of the most abundant species in natural history collections,

744 specimens were often previously been determined as T. nevadus. Trogloderus major is sympatric with T. tuberculatus and T. vandykei, where they are often taken in mixed series. This is the species from the Nevada Test Site referred to as T. costatus nevadus in Tanner and Packham

747 (1965), who reported this species active from March through October, with a distinct peak in 748 abundance in August.

750

\section{Trogloderus nevadus La Rivers, 1943}

751

Figures 6G, 7E, 9 
752 Diagnosis. The combination of a punctate, evenly convex pronotum, tuberculate propleurae and

753

754

755

756

757

758

759

760

761

762

763

764

765

766

767

768

769

770

771

772

773

774

775

776

777

778

779

780

781

782

783

784

785

786

787

788

789

790

791

epistoma, and the frontoclypeal suture forming a complete transverse ridge will separate this species from all congeners but some specimens of $T$. arcanus. See the key characters and diagnosis of the latter species to further separate the two.

Redescription. As genus with the following: Length $8.5-10 \mathrm{~mm}$, width $3.5-4 \mathrm{~mm}$. Head. Epistoma and frons tuberculate throughout, lacking distinct punctures; frontoclypeal suture forming complete transverse ridge. Thorax. Pronotum evenly convex dorsally; heavily punctate throughout, punctures longitudinally oval, tending to coalesce anteriorly; lateral margins moderately arcuate, sinuate in basal $1 / 5$; posterior angles obliquely acute, small; anterior fovea weakly impressed, connected to posterior fovea; posterior fovea similarly weakly impressed, sometimes slightly deeper. Propleurae granulately tuberculate throughout, always with tubercles present anteriorly underneath pronotal margin. Prosternal process horizontal, usually distinctly margined along entire outline, forming evenly tapering triangle behind posterior procoxal margin. Elytral costae moderately produced, intervals punctate, lacking transverse ridges; elytral suture weakly elevated in posterior $1 / 2$. Abdomen. Abdominal depression indistinct to weak in females, discernable only on ventrite I, relatively weak in males, discernable on ventrites I-II, but lateral margin forming ridge only on ventrite I. Male terminalia. Parameres (Fig. 7E) triangular, evenly tapering from base to apex.

Variation. This species is fairly constant throughout its range. The pronotal foveae are sometimes moderately pronounced, generally in larger and more roughly sculptured individuals, whereas the typical form has the foveae very weakly depressed.

Distribution. Fig. 9. This species is distributed throughout the northern Great Basin, throughout the Lake Lahontan drainage and into the Snake River Plains.

Type material. Holotype male from Pyramid Lake Dunes, Washoe County, Nevada, not seen. Deposited in Ira La Rivers' collection (La Rivers 1943: 439), which was later deposited at the state collection of Nevada in Reno, the type was not located there (K. Tonkel, personal communication), nor found at the CASC where a sizable amount of La Rivers material is located. The description, examined paratypes, and abundant subsequent collecting from the type locality leave no doubt as to this species identity.

Material examined. 332 specimens including 4 paratypes (see Supplemental Data S1, Supplemental Data S2 or SCAN for full specimen data ).

Remarks. This species is broadly sympatric with $T$. costatus, but seemingly has a slightly broader range, extending south to the dunes around Walker Lake and north to Pyramid Lake. It is surprising that no specimens were found from southeastern Oregon, which seems to have

Peer) reviewing PDF | (2019:06:38531:1:1:NEW 26 Sep 2019) 
792

793

794

795

796

\section{7}

798

799

800

801

802

803

804

805

806

807

808

809

810

811

812

813

814

815

816

817

818

819

820

821

822

823

824

825

826

827

828

829

830

831

appropriate habitat without any significant barriers to dispersal. Increased collecting efforts may produce specimens from the periphery of the currently known range. Many specimens referred to the present species in natural history collections belong to the herein described species with punctate pronota.

\section{Trogloderus skillmani Johnston, New Species} urn:1sid:zoobank.org:act:63C947D5-73A7-4188-A430-247B04AFD633

Figures 6D, 7F, 9

Diagnosis. This species can be recognized by the relatively evenly tuberculate pronotum, lack of subapical elytral tubercles, and relatively evenly tapering male parameres. This species is most similar to $T$. verpus, which can be separated by the male terminalia (parameres strongly constricted near base in $T$. verpus, parameres not strongly constricted, evenly tapering to apex in T. skillmani). The present species is also fairly similar to T. warneri, which can be separated by the pronotal characters given under the diagnosis for that species.

Description. As genus with the following: Length $9.5-12.5 \mathrm{~mm}$, width $3.5-4 \mathrm{~mm}$. Head. Epistoma and frons tuberculate throughout; mesal region of frons on same plane as clypeus; frontoclypeal suture not or weakly forming transverse ridge. Thorax. Pronotum relatively evenly convex dorsally; evenly tuberculate throughout, lateral regions of pronotum more or less depressed, but similarly tuberculate as remainder of disc; lateral margins fairly evenly arcuate, recurved just before posterior angles; posterior angles small, acute; posterior margin straight, mesal region forming continuous line laterally to terminus of posterior angle. Propleurae evenly and densely tuberculate throughout. Prosternal process short, usually offset dorsad from plane of prosternum between procoxae. Elytral costae moderately to strongly produced; intervals usually tuberculate, tubercles originating from center of interval as well as lateral faces of costae; elytral suture elevated in poster $3 / 4$, nearly as produced as discal costae. Abdomen. Abdominal depression lacking in both sexes. Male parameres (Fig. 7F) narrowly triangular, evenly to slightly arcuately converging to apex.

Variation. This species as circumscribed here is the most widespread of any Trogloderus and has some significant variation accordingly. Specimens near the type locality, from northern Arizona and southern Utah, tend to have extremely tuberculate elytra intervals, strongly produced elytral costae, and small prosternal processes. Specimens from more typical great basin regions of Utah and Nevada (e.g., Little Sahara dunes, Crescent Dunes) tend to be less strongly sculptured on the elytra and have slightly enlarged prosternal processes. Specimens from the far western end of the distribution near Mono Lake have stronger elytral sculpturing and large, nearly horizontal prosternal processes. The posterior pronotal angles are always acute and usually form a continuous posterior margin to the pronotum, but occasionally the angles are obliquely oriented. This seems to be individual variation and not tied to geography. 
833 Distribution. Fig. 9. This species has the widest distribution of any Trogloderus, extending from

834 the Coral Pink sand dunes and surrounding regions north to the Little Sahara Dunes and west to 835 Mono Lake.

836

837 Type material. Holotype. "USA: AZ: Mohave Co. / 6m E Colorado City / Rosy Canyon Road / 838 1.5m S UT state line / 12-VII-2016 / F.W. \& S.A. Skillman”, “ARTSYS0007053”, bearing red 839 holotype label. Deposited in the ASUHIC, catalog number ASUHIC0101565. Paratypes. 920 840 specimens from the western regions of the Colorado Plateau around the Coral Pink Sand Dunes, 841 Hurricane, and Toquerville Utah, bearing blue paratype labels (see Supplemental Data S1, 842 Supplemental Data S2 or SCAN for full specimen data).

843

844 Other material. 182 specimens from the Northern and Western reaches of this species range.

845

846 Etymology. This species is named after Frederick W. Skillman, who both collected the holotype 847 and has been a constant help throughout this study. His generous sharing of specimens, 848 knowledge of natural history, and long drives to remote sand dunes are greatly appreciated.

849

850

Remarks. A broader molecular sampling and increased collections from Nevada localities may

851 eventually find this taxon to be a cryptic species complex. Apparently able to cross boundaries

852 that limit other species of Trogloderus, T. skillmani may be more adept at dispersing than its

853 congeners.

854

855

856

Trogloderus tuberculatus Blaisdell, 1909

857

=Trogloderus costatus pappi Kulzer, 1960

858

859 Figures 6A, 7G, 10

Diagnosis. This species can be readily identified by the presence of tubercles on the pronotum

860 and the large, subapical tubercle at the terminus of the outer costa on each elytron. The present

861 species can be further separated from the others with tuberculate pronota by the thick, raised

862 ridges demarking the lateral margins and boundary between the pronotal foveae.

863

864 Redescription. As genus with the following: Length $10.5-12 \mathrm{~mm}$, width 4-4.5mm. Head.

865 Epistoma and frons tuberculate throughout, lacking distinct punctures above antennal insertion; 866 frontoclypeal suture forming complete, though gentle, transverse ridge; frontal tubercle covered 867 with smaller tubercles. Thorax. Pronotum with dorsal silhouette appearing somewhat bilobed in 868 anterior view; distinctly tuberculate throughout; lateral margins strongly arcuate, recurved just 869 before posterior angles; posterior angles obliquely acute, small; foveae well demarked laterally 870 by continuous strongly elevated longitudinal ridges; anterior fovea distinct, smooth, separated 871 from posterior fovea by strongly elevated ridge; posterior fovea circular, usually smooth mesally. 
872 Propleurae fairly smooth, with dorsal longitudinal row of irregular tubercles running just beneath

873 pronotal margin; often tuberculate on bulge covering procoxae. Prosternal process small,

874 subtriangular, not margined laterally, slightly offset dorsad of prosternum between procoxae.

875 Elytral costae strongly produced, crenulate; intervals with deep punctures, lacking transverse

876 ridges; each elytron with subapical tubercle, formed by terminus of outer elytral carina, often

877 formed by confluence of outer 1-3 costae; elytral suture very weakly produced, much shorter

878 than discal carinae. Abdomen. Ventrites tuberculate throughout; abdominal depression weak,

879 present on ventrites I-II in both sexes, without marginal ridge, usually somewhat smooth in

880 males. Male terminalia. Parameres (Fig. 7G) narrowly triangle, more or less evenly tapering to

881 apex.

882

883

884

885

886

887

888

889

890

891

892

893

894

895

896

897

898

899

900

901

902

Variation. The subapical elytral tubercles, unique to this species of Trogloderus, are somewhat variable. It is always made up of the thickened terminus of the outer elytral costa and is variably formed by the confluence of any combination of the outer three costae. This seems to be individual variation and not correlated with geography. Specimens from Kelso Dunes (the only confirmed locality where T. tuberculatus is sympatric with another species, T. major) are distinctly smaller than all other examined localities and possess less developed subterminal elytral tubercles.

Distribution. Fig. 10. This species is found in the Mojave Desert, and is generally found around the periphery from the western high desert reaches and in the northern Death Valley region.

Types. The holotype of T. tuberculatus Blaisdell, collected from "L.A. County, California," was examined at the USNM. The holotype of T. costatus pappi Kulzer, from Lancaster, Mojave Desert, Southern California, was not examined (see remarks below).

Material examined. 41 specimens (see Supplemental Data S1, Supplemental Data S2 or SCAN for full specimen data).

903

Remarks. Similar to T. costatus, it is remarkable that this species, the least common in natural history collections, was the second species described in the genus. Papp and Pierce (1960)

904 reported this species feeding on stored chicken feed in Lancaster, California. Specimens from

905 this collecting event (the largest known for this species, at least ten individuals) were sent to the

906 Frey museum in Germany (Papp 1961: 35), which became the type series for Trogloderus costatus pappi Kulzer (Kulzer 1960: 331). Though the type itself was not examined, seven

907 specimens from Papp's (1961) original series were studied and are all certainly conspecific with $908 T$. tuberculatus as herein circumscribed. This species was very difficult to recollect, particularly

909 due to lack of suitable habitat. The western Mojave Desert has been largely developed, and after 910 multiple targeted trips to the region only a single, ca. 0.25 acre, dune near California City was

911 found to support a population of this species. Most specimens in natural history collections 
912 determined to this species (or subspecies as T. costatus tuberculatus) actually belong to other

913 tuberculate species described herein.

914

915 Trogloderus vandykei La Rivers, 1946

$916=$ Trogloderus costatus mayhewi Papp, 1961

917 Figures $1,7 \mathrm{H}, 10$

918

919 Diagnosis. This species can be readily separated from all other Trogloderus by the pronotal 920 dorsum being bilobed when viewed from the front. Its pronotum is also punctate and more 921 broadly explanate than any of its congeners. Most similar to and sympatric with T. major, the 922 two can be readily separated by the given characters.

923

924

925

926

927

928

929

930

931

932

933

934

935

936

937

938

939

940

941

942

943

Description. As genus with the following: Length $9-11.5 \mathrm{~mm}$, width $3.5-4.5 \mathrm{~mm}$. Head. Epistoma punctato-tuberculate; frons smooth, mesal region on same plane as clypeus; frontoclypeal suture not forming complete ridge, obsolete at least mesally; frontal tubercle punctate, not very prominent. Thorax. Pronotal dorsum bilobed in anterior view; pronotum strongly explanate, punctate, punctured becoming irregular tubercles laterally; lateral margins strongly and evenly arcuate, recurved just before posterior angles; posterior angles obliquely acute, small; foveae bounded by raised lobed on either side, anterior fovea moderately impressed, forming continuous channel with posterior fovea, posterior fovea usually slightly deeper. Propleurae smooth, lacking tubercles throughout, occasionally with granulate tubercles ventrally around procoxae. Prosternal process horizontal, prominent, strongly margined, especially in males, forming evenly tapering triangle behind posterior procoxal margin. Elytral costae moderately produced, intervals relatively smooth, bering two rows of punctures, lacking any transverse ridges; elytral suture not at all elevated, situated in concavity formed by inner discal costae. Abdomen. Abdominal depression very strong in both sexes, exceedingly so in males, visible on ventrites I-III, demarked by strongly punctate lateral ridges which curve mesad and form distinct posterior margin on ventrite III. Male terminalia. Parameres (Fig. 7H) more or less arcuately converging from base to apex, apical $1 / 2$ subparallel.

944

Variation. This species exhibits consistent morphology throughout its range. Occasionally smaller specimens are observed in which the pronotum appears less explanate, but this form 945 the larva.

946

947 Distribution. Fig. 10. Eastern and central Mojave Desert, especially abundant in dunes along the 948 Colorado River. 
950 Types. The holotype of T. costatus vandykei La Rivers, from Baker, San Bernardino County, 951 California, was examined at the CASC. The holotype of T. costatus mayhewi Papp, from Dale 952 Dry Lake, San Bernardino County, California, was examined at the LACM.

953

954

955

956

957

958

959

960

961

962

963

964

965

966

967

968

969

970

971

972

973

974

975

976

977

978

979

980

981

982

983

984

985

986

987

988

989

Material examined. 327 specimens (see Supplemental Data S1, Supplemental Data S2 or SCAN for full specimen data).

Remarks. This species ranges the furthest south of any Trogloderus members, having been collected just north of Yuma, Arizona. Trogloderus vandykei has never been collected from the Algodones or other sand dunes in the Colorado Desert (Johnston et al. 2018). This is perhaps simply because they have not yet dispersed to these dunes. While there may be some other competitive or environmental factors at play, both $T$. vandykei and other congeners persist very well in regions of seemingly similar intense annual heat and dry conditions (e.g., Death Valley, Wiley's Well, Bouse Dunes, etc.).

\section{Trogloderus verpus Johnston, New Species}

urn:lsid:zoobank.org:act:E413CFD5-4634-4321-8D85-03F9C8D85FEE

Figures 6B, 7I, 10

Diagnosis. This species can be recognized by the evenly tuberculate pronotum, lack of subapical elytral tubercles, and the male parameres being strongly constricted basally. It is most similar to T. skillmani, which can be separated by the male terminalia (parameres not constricted in $T$. skillmani).

Description. As genus with the following: Length $9.5-11.5 \mathrm{~mm}$, width $3.5-4.5 \mathrm{~mm}$. Head. Epistoma and frons evenly tuberculate, tubercles often irregularly shaped; frontoclypeal suture not forming complete transverse ridge, mesal region of frons more or less on same plane as clypeus. Thorax. Pronotum evenly convex dorsally, occasionally with lateral regions slightly flattened posteriorly; lateral marginsfairly evenly arcuate, recurved just before posterior angles; posterior angles small, acute; posterior margin usually straight, mesal region forming continuous line to terminus of posterior angle. Propleurae densely and evenly tuberculate throughout. Prosternal process acute, usually small, offset dorsad from plane of prosternum between procoxae. Elytral costae moderately to strongly developed, intervals variable from smooth to moderately tuberculate; elytral suture moderately to strongly elevated in posterior $1 / 2$, usually distinctly shorter than discal costae. Abdomen. Abdominal depression absent in both sexes. Male Terminalia. Parameres (Fig. 7I) strongly constricted near basal 1/6, then narrowly and evenly tapered to apex.

Variation. This species is fairly consistent across its range, but presents some variation in the elytral sculpturing. In some specimens the intervals between discal costae are noticeably 
990 tuberculate, while most are smooth. The elytral suture is usually less strongly elevated than the 991 discal costae, but in some New Mexico populations (e.g., near Farmington), it is nearly the same 992 height as the discal costae. Specimens from the sand dunes near Moenkopi, where they are 993 sympatric with $T$. warneri, are distinctly smaller and less roughly sculptured than anywhere else 994 in its range.

995

996

997 998

999

1000

1001

1002

1003

1004

1005

1006

1007

1008

1009

1010

1011

1012

1013

1014

1015

1016

1017

1018

1019

1020

1021

1022

1023

1024

1025

1026

1027

1028

1029

Distribution. Fig. 10. This species is broadly distributed throughout the Colorado Plateau, from Moenkopi, Arizona east to central New Mexico and north to the Killpecker Dunes in Wyoming.

Type material. Holotype. "USA: UT: Grand Co. / 22m NW Moab, Dubinky / Well Rd. @ Dubinky Well / 25-VI-2016 / Skillman \& Johnston”, “ARTSYS0007055”, bearing red holotype label. Deposited in the ASUHIC, catalog number ASUHIC0101566. Paratypes. 185 specimens from throughout the species range bearing blue paratype labels (see Supplemental Data S1, Supplemental Data S2 or SCAN for full specimen data).

Etymology. This species name is given for the strongly constricted male parameres, which look as though a portion has been cut away from the fairly regularly triangular shape found in the rest of the genus (Brown 1956).

Remarks. The remarkably small specimens from near Moenkopi may be an example of competition forcing allometry. Indeed, the specimens of T. warneri from Moenkopi are a very similar size to specimens of $T$. verpus from the rest of its range.

\section{Trogloderus warneri Johnston, New Species}

urn:1sid:zoobank.org:act:9D1E0BF2-F309-4A98-A64C-5708CFE864D0

Figures 6C, 7J, 10

Diagnosis. This species can be recognized by the combination of a tuberculate pronotum and large, inflated posterior pronotal angles. The species can be further recognized by the depressed lateral regions of the pronotum lacking tubercles, the lack of an abdominal impression, and the lack of subapical elytral tubercles.

Description. As genus with the following: Length $9-11 \mathrm{~mm}$, width $3.5-5 \mathrm{~mm}$. Head. Epistoma and frons tuberculate throughout, frontoclypeal suture not developed as transverse ridge, mesal region of frons on same plane as clypeus. Thorax. Pronotum relatively evenly conxex dorsally; heavily tuberculate; disc laterally depressed, usually lacking tubercles, especially posteriorly; lateral margins arcuate, more strongly narrowed posteriorly, recurved just before posterior angles; posterior angles large, obliquely angles, usually well inflated, sometimes broadly acute. Propleurae evenly tuberculate, tubercles fairly large and rounded. Prosternal process short, triangular, offset dorsad from plane of prosternum between procoxae. Elytral costae well 
1030 developed, intervals with deep punctures, sometimes giving appearance of short transverse

1031

1032

1033

1034

1035

1036

1037

1038

1039

1040

1041

1042

1043

1044

1045

1046

1047

1048

1049

1050

1051

1052

1053

1054

1055

1056

1057

1058

1059

1060

1061

1062

1063

1064

1065

1066

1067

1068

1069

ridges; elytral suture weakly to moderately produced in posterior half, always shorter than discal costae. Abdomen. Ventrites tuberculate; without abdominal depression, ventrite I sometimes smooth mesally in males. Male terminalia. Parameres (Fig. 7J) subparallel in basal 1/5, then arcuately converging to apex.

Variation. The pronotum, while diagnostic for this species, is somewhat variable in the specimens examined. The typical form has very strongly inflated posterior angles and the disc distinctly depressed and lacking tubercles laterally. In some specimens the posterior angles are less inflated and the depressed lateral region is much smaller, tending to be restricted to the posterior third. However, these reduced characters were distinctly discernable in all specimens studied, reliably separating them from other Trogloderus species.

Distribution. Fig. 10. Distributed in the western Colorado Plateau, the species seems bounded on the west by the Kaibab Plateau, and are distributed as far east as Moenkopi, Arizona.

Type material. Holotype. "USA:AZ:Coconino Co. / Hwy. 264 2.2mi SE jct / US160; $36^{\circ} 05^{\prime} 57^{\prime} \mathrm{N}, / 111^{\circ} 12^{\prime} 03^{\prime}$ 'W; dunes at / night; April 20, 2012; W.B. Warner, J.P. Gruber". "ARTSYS0007054", bearing red holotype label. Deposited in the ASUHIC, catalog number ASUHIC0101563. Paratypes. 237 specimens from across the species range (see Supplemental Data S1, Supplemental Data S2 or SCAN for full specimen data).

Etymology. I am honored and thankful to name this species for William B. Warner, an ardent collector, coleopterist, and natural historian. His assistance and encouragement throughout this project in both the field and the lab are greatly appreciated.

Remarks. This species has a relatively small geographic range, yet extends across the eastern reaches of the Grand Canyon. This is perhaps the reason for the observed moderate genetic diversity within the species. Most specimens in natural history collections have been determined as T. tuberculatus.

\section{Results}

\section{Phylogenetic reconstruction}

Both maximum likelihood and Bayesian analyses converged on a single topology with moderately strong support throughout (Fig. 11). Within the outgroups, the genus Eleodes Eschscholtz was notably recovered as paraphyletic with respect to the genera Neobaphion Blaisdell, Embaphion Say, Lariversius Blaisdell, and Trogloderus. This raises broader questions regarding the naturalness of the current classification of the tribal concept as a whole (Bousquet et al. 2018); however, the sampling for this study is not sufficient to justify more substantive

Peer) reviewing PDF | (2019:06:38531:1:1:NEW 26 Sep 2019) 
1070 classificatory changes. Trogloderus was recovered as monophyletic, and is further subdivided 1071 into two strongly supported clades - i.e., (1) the "tuberculate-pronotum clade" containing all 1072 species that bear distinct tubercles on the pronotal disc, and (2) the "reticulate-pronotum clade" 1073 containing all species whose pronotal discs have deep punctures that make the intervals appear to 1074 be elevated into reticulate sculpturing. All Trogloderus species as circumscribed above were 1075 similarly found to be monophyletic with posterior probabilities of 1 and bootstrap support of 95 1076 or higher.

1077

1078

1079

1080

1081

1082

1083

1084

1085

1086

1087

1088

1089

1090

1091

1092

1093

1094

1095

1096

1097

1098

1099

1100

1101

1102

1103

1104

1105

1106

1107

1108

1109 Phylogenetic dating analyses

The Trogloderus tuberculate-pronotum clade contains four species and is well resolved (Fig. 11), with internal nodes between species all having posterior probabilities greater than 0.95 and bootstrap values above 85 . The relationships between these species imply an east-to-west diversification pattern. The easternmost species, T. verpus (Fig. 10) known from the Colorado Plateau, is recovered as sister to a clade containing the remaining three species. The latter clade shows the same trend with its easternmost species, T. warneri (Fig. 10) distributed east of the Kaibab Plateau, sister to the species T. skillmani (Fig. 9) and T. tuberculatus (Fig. 10), which are distributed west of the Kaibab Plateau.

The Trogloderus reticulate-pronotum clade contains six species (Fig. 11) with notably western distributions, ranging from the Mojave Desert to the Great Basin. The relationships between these species are less well resolved than for those of the tuberculate-pronotum clade, though each species is supported as monophyletic with posterior probabilities of 1 and bootstrap support values of 95 or higher. While analyses converged on a single topology, the underlying data do not give unequivocal support to the relationships of the early-diverging species. Trogloderus arcanus, T. vandykei, and T. nevadus are inferred to have diverged before a clade containing the other three reticulate-pronotum species. However, these branches all have posterior probabilities lower than .95 and bootstrap support values below 75. The clade consisting of T. kandai, $T$. costatus, and T. major is strongly supported with a posterior probability of 1 and a bootstrap support value of 83 . The reticulate-pronotum clade seems to indicate a latitudinal pattern to diversification. Neither of the two sympatric pairs of species in this clade, the southern $T$. vandykei with T. major and the northern T. costatus with T. nevadus, form monophyletic groups. This supports the notion that multiple vicariant or dispersal events between these regions were involved in the diversification of this lineage.

Trogloderus arcanus and T. nevadus exhibit longer branch lengths between sampled populations within the species than any others sampled for this study (Fig. 11). This may simply be due to limited sampling, but further molecular and morphological investigations from the undersampled regions of Nevada may provide evidence for the two herein circumscribed species to represent more complex taxonomic groups. 
1110 Trogloderus is here inferred to be relatively young, with the most recent common ancestor 1111 (MRCA) for the genus occurring during the late Miocene or earliest Pliocene (Fig. 12).

1112 Furthermore, most speciation events are inferred to have taken place during the Pleistocene.

1113 Based on these inferences, it seems evident that La River's (1946) hypothesis of an ancient

1114 lineage approaching extinction can be refuted for Trogloderus. Instead, Trogloderus seems to

1115 postdate the Neogene Uplift, having originated and diversified in conjunction with the recent

1116 desert formations of western North America (Wilson and Pitts 2010).

1117

1118

Dating analyses for Trogloderus using BEAST (Fig. 12A-B) inferred comparatively older dates

1119 than RelTime (Fig. 12C-D) but are not particularly reliable, having failed to converge after 500

1120 million generations. The MRCA of Trogloderus was dated to 10.27 mya, and ages for both calibrated nodes were older than expected, namely 4.03 mya for the Inyo-White mountains calibration, with the prior mean set at 2.5mya, and 1 mya for the Grand Canyon calibration, with a prior mean set at .83mya. The estimated sample sizes for mutation rates did not exceed 10 and those for calibration times and tree height were well under 100. Additional analyses under different locus partition and model schemes and modified taxon inclusion similarly failed to converge. This may be due either to limitations with the underlying molecular dataset, or because the coalescent-based priors may be inappropriate for this class of data. The results using the Yule model are shown in Fig. 12A-B, displaying the median node age and $95 \%$ highest posterior density respectively. Due to this lack of convergence, the timetree from RelTime was used for subsequent historical biogeographic inference.

1131

1132

1133

1134

1135

1136

1137

1138

1139

1140

1141

1142

1143

1144

1145

1146

1147

1148

RelTime analyses infer Trogloderus to have originated in the earliest Pliocene with most current species arising during the mid-Pleistocene. Divergence estimates from RelTime were consistently later than those inferred from BEAST, with the MRCA of Trogloderus dated to 5.2 mya, and the dates of 2.5 mya and 0.56 mya for the calibration clades split by the Inyo-White mountains and the Grand Canyon respectively. Median node ages and 95\% confidence intervals inferred from RelTime are shown in Fig. 12C-D respectively.

The Sierra Nevada mountains offer one line of geological evidence for the age of Trogloderus to be closer to 5 my as the RelTime analysis infers. The timing of the uplift of the Sierra Nevada Mountains remains contested in the geological literature (Wilson and Pitts 2010), but significant evidence suggests that the majority of the uplift occurred between 5-8 mya and was a primary force in creating the Great Basin and Mojave deserts (Jones et al. 2004, Wilson and Pitts 2010). Were Trogloderus older than this uplift event, we might expect them to be present outside of the intermountain region. Indeed, members of the genus are able to endure cold winters from central Wyoming as well as the extreme heat from Death Valley and surrounding environs. Beyond living in sandy substrates, there are no other clear environmental limits to their distribution. 
1149 The MRCA of all included Amphidorini taxa was dated to 7.97 mya with a $95 \%$ confidence

1150

1151

1152

1153

1154

1155

1156

1157

1158

1159

1160

1161

1162

1163

1164

1165

1166

1167

1168

1169

1170

1171

1172

1173

1174

1175

1176

1177

1178

1179

1180

1181

1182

1183

1184

1185

1186

1187

1188 interval of 1.5-14.5 mya using RelTime. This date range, though the first inferred for this fossillacking tribe, is younger than expected based on phylogenetic work at the family level. The newworld Amphidorini appear to be sister the old-world tribe Blaptini Leach, 1815 (Kanda 2017). The latter was estimated by Kergoat et al. (2014) to have an origin closer to 55mya, but no members of Amphidorini were included in that study. The young age inferred here for the tribe may again be a symptom of low species-level taxon sampling. Hypotheses about the origin and diversification of Amphidorini will have to wait for future studies with a broader scope.

\section{Historical biogeographic estimation}

The MRCA of Trogloderus was inferred to inhabit the Colorado Plateau (Fig. 13), where the majority of the tuberculate-pronotum clade still resides. The ancestors of the reticulate-pronotum clade are inferred to have dispersed into the Lahonton Trough, and from there radiated into the Mojave Desert, Great Basin, and Owens Valley. Three separate radiations into the Mojave Desert are inferred for the three species sympatric there. The insights given by this biogeographic estimation for specific subregions are discussed in detail below.

Historical biogeographic estimation in BioGeoBEARS supports the use of a model incorporating founder-event jump dispersal (Matzke 2014). This process is not only important for taxa distributed across islands (Matzke 2014, Zhang et al. 2017), but also for taxa living on sand dunes or other isolated habitats which can functionally act the same as islands (Van Dam and Matzke 2016). The DEC model resulted in a most likely estimation with a log likelihood score of -43.6. The DEC $+\mathrm{J}$ model, which employs a single extra parameter for jump dispersal, produced an estimation with a $\log$ likelihood of -26.8. By performing a likelihood ratio test (Huelsenbeck and Crandall 1997), the DEC+J model provides a significantly better fit to the data than the DEC model at a P-value of $1 \mathrm{e}-5$.

\section{Discussion of the biogeography of the Intermountain Region}

The historical biogeography of Trogloderus supports the distinction of the Lahontan Trough as a unique element of the Intermountain Region, and is the first to provide molecular and historical biogeographic support for the area to play a part in the migration of clades throughout the intermountain region. The appraisal of the biogeography of the Intermountain Region by Reveal (1979) was a landmark study based largely on floristic distributions and extensive field observations. A comprehensive biogeographic review of the region has not been published since. One major hypothesis put forth in this work is that the Lahontan Trough acts as a migration route into and out of the region. Following the establishment of the Lahontan Trough as a biogeographic entity by Reveal (1979), multiple studies have found populations from this area to 
1189 be distinct from populations of the same species from the Mojave and Great Basin deserts 1190 (Britten and Rust 1996, Hafner et al. 2006), and at least one psammophilic plant is unique to the

1191

1192

1193

1194

1195

1196

1197

1198

1199

1200

1201

1202

1203

1204

1205

1206

1207

1208

1209

1210

1211

1212

1213

1214

1215

1216

1217

1218

1219

1220

1221

1222

1223

1224

1225

1226

1227

1228 area (Pavlik 1989). Together, these studies suggest that the Lahontan Trough is likely to play an important role in the evolutionary history of any sand-dune restricted or dispersal-limited taxa in the region.

The newly described Trogloderus kandai is the first sand-dune species known to be restricted to the southern Owens Valley. The region has been relatively well studied for changes in plant communities (Koehler and Anderson 1995, Elmore et al. 2003) and fish conservation (Galicia et al. 2015). However, the sand dunes, which are comprised of particles originating from the surrounding Sierra Nevada and Coso mountains (Lancaster et al. 2015), have not had any beetle species reported only from them (Andrews et al. 1979). Whether T. kandai is truly the only species restricted to this habitat or if there are others waiting to be described, additional faunal surveys of the sand dunes around the dry Owens Lake should be completed to understand what further importance this area may have for Intermountain biodiversity.

The three sympatric species of Trogloderus with independent dispersal events into the Mojave Desert are consistent with the inference of an eastern origin for the genus with a continual movement westward. The relatively recent timing for incursions into the Mojave Desert is also consistent with the fact that Trogloderus does not range south into the dunes of the Colorado and Sonoran deserts (Aalbu and Smith 2014, Johnston et al. 2018). The relationships of the dune systems within the Mojave Desert were subdivided and well-tested by Van Dam and Matzke (2016), but are here treated as a single unit. The barriers between these sand systems within this area seem to not be a major limiting factor for Trogloderus as T. tuberculatus and T. major are fairly evenly spread throughout.

The predicted footprint of the prehistoric lakes making up the Bouse Embayement is almost identical to the distribution of $T$. vandykei. This region, spanning along the lower Colorado River between Arizona and California (Wilson and Pitts 2010), was covered by three large prehistoric lakes that ran from just north of present-day Bullhead City, Arizona south past Blythe, Arizona. The drainage was bounded along the south by the Chocolate Mountains and extended west into the Bristol basin (Spencer et al. 2013). These lakes likely appeared around 4.9 mya and drained relatively shortly thereafter when the Colorado River eventually connected to the Gulf of California (Spencer et al. 2013). It is very likely that the sand derived from these lakes and the geological boundaries that formed their drainage basins have shaped the diversification and distribution of T. vandykei. The lakes are also implicated in genetically structuring the populations of a desert scorpion (Graham et al. 2017). The Bouse Embayment is further supported as a separate biogeographic entity based on the distribution of other psammophilic Tenebrionidae. Though the Algodones dunes are in extremely close proximity to the southern edge of the Bouse Formation, not only does Trogloderus not cross over the Chocolate Mountains 
1229 and occur there, but multiple species restricted to the Algodones and Gran Desierto de Altar

1230

1231

1232

1233

1234

1235

1236

1237

1238

1239

1240

1241

1242

1243

1244

1245

1246

1247

1248

1249

1250

1251

1252

1253

1254

1255

1256

1257

1258

1259

1260

1261

1262

1263

1264

1265

1266

1267

1268

similarly do not extend north into the Bouse Embayment (Johnston et al. 2018).

Within the Colorado Plateau, three subregions are suggested by Trogloderus distributions. The distribution of the eastern $T$. verpus is somewhat surprising in that no previous biogeographic hypotheses were found to explain why it does not range as far west as the Vermillion Cliffs. One explanation is competitive exclusion within the genus, and this is somewhat supported by the populations near Moenkopi, Arizona. Both T. verpus and T. warneri occur on these dunes, and all studied specimens of $T$. verpus were significantly smaller than those of $T$. warneri. However, throughout the rest of its range, $T$. verpus has roughly the same body size as $T$. warneri. Another possible explanation is that the Kaiparowitz Formation around Grand Staircase-Escalante National Monument acts as a barrier between sand systems from the Kaibito and Moenkopi plateaus of north-central Arizona and those from the northern reaches of the greater Colorado Plateau. The Kaiparowitz Formation, along with the Wasatch Mountains, formed the western boundary of the western interior seaway during the Cretaceous (Hettinger et al. 1996, Roberts 2007) and is implicated in the speciation of large dinosaurs at the time (Sampson et al. 2010). No studies of modern taxa that study this boundary were found. Even though the Colorado River and its tributaries have carved large canyons through this formation, it may still be a significant barrier between sand-dune restricted taxa. The third subregion is separated from the others by the Kaibab Plateau. This tall formation separates $T$. warneri from its eastern T. skillmani and $T$. tuberculatus. The effect of the Kaibab Plateau on dune-dwelling taxa is apparently similarly unstudied.

\section{Conclusions}

The revision and historical biogeography of Trogloderus help to bring the biogeographic trends of the Intermountain Region into focus. The cohesive distributional patterns of Trogloderus species build upon the foundational work of Reveal (1979) and highlight regions that should be critically evaluated during future phylogenetic, taxonomic, and biogeographic studies. It is hoped that continued research on the under-studied biodiversity of the Intermountain Region will continue to bring clarity to the relationships between sand-dune systems of western North America.

\section{Acknowledgements}

The author thanks Aaron Smith and Kojun Kanda for their sharing of tenebrionid knowledge and assistance with molecular analyses. Nico Franz supported this study from conception to completion and offered valuable feedback on the manuscript. William Warner and Frederick Skillman are gratefully acknowledged for their support during field work and along with many curators and managers of natural history collections provided the necessary specimens for this study. Comments and suggestions from three reviewers provided improvements to earlier versions of this manuscript. 
1269

1270

1271

1272

1273

1274

1275

1276

1277

1278

1279

1280

1281

1282

1283

1284

1285

1286

1287

1288

1289

1290

1291

1292

1293

1294

1295

1296

1297

1298

1299

1300

1301

1302

1303

1304

1305

1306

1307

1308

\section{References}

Aalbu RL, Triplehorn CA, Campbell JM, Brown KW, Somerby RE, Thomas DB (2002) 106. Tenebrionidae Latreille 1802. In: Arnett RH, Thomas MC, Skelley PE, Frank JH (Eds) American beetles. Volume 2. Polyphaga: Scarabaeoidea through Curculionoidea. CRC Press, Boca Raton, 463-509

Aalbu RL, Smith AD (2014) The Tenebrionidae of California: A time sensitive snapshot assessment. ZooKeys 415: 9-22. https://doi.org/10.3897/zookeys.415.6523

Aalbu RL, Smith AD, Triplehorn CA (2012) A revision of the Eleodes (subgenus Caverneleodes) with new species and notes on cave breeding Eleodes (Tenebrionidae: Amphidorini ). Annales Zoologici (Warszawa) 62: 199-216. https://doi.org/10.3161/000345412X652729

Andrews FG, Hardy AR, Giuliani D (1979) The coleopterous fauna of selected California sand dunes. California Department of Food and Agriculture, Sacramento, California.

Bachman SB (1979) Pliocene-Pleistocene break-up of the Sierra Nevada-White-Inyo Mountains block and formation of Owens Valley. Geology 6: 461-463. https://doi.org/10.1130/00917613(1978)6<461:PBOTSN $>2.0 . \mathrm{CO} ; 2$

Blaisdell FE (1909) A monographic revision of the Coleoptera belonging to the tenebrionide tribe Eleodiini inhabiting the United States, Lower California, and adjacent islands. Bulletin of the United States Museum No.63. vi +524 pp. (+ 13 pls $)$.

https://doi.org/10.5962/bhl.title.48543

Bouchard P, Bousquet Y, Davies AE, Alonso-Zarazaga MA, Lawrence JF, Lyal CHC, Newton AF, Reid CA, Schmitt M, Slipinski SA, Smith AB (2011) Family-group names in Coleoptera (Insecta). ZooKeys 88: 1-972. https://doi.org/10.3897/zookeys.88.807

Bouchard P, Lawrence JF, Davies A, Newton AF (2005) Synoptic classification of the world Tenebrionidae (Insecta: Coleoptera) with a review of family-group names. Annales Zoologici (Warszawa) 55: 499-530.

Bouckaert R, Heled J, Kühnert D, Vaughan T, Wu C-H, Xie D, Suchard MA, Rambaut A, Drummond AJ (2014) BEAST 2: A Software Platform for Bayesian Evolutionary Analysis. PLoS Computational Biology, 10(4), e1003537. 
1309

1310

1311

1312

1313

1314

1315

1316

1317

1318

1319

1320

1321

1322

1323

1324

1325

1326

1327

1328

1329

1330

1331

1332

1333

1334

1335

1336

1337

1338

1339

1340

1341

1342

1343

1344

1345

1346

1347

1348

Bousquet Y, Thomas DB, Bouchard P, Smith AD, Aalbu RL, Johnston MA, Steiner Jr. WE (2018) Catalogue of Tenebrionidae (Coleoptera) of North America. ZooKeys 728: 1-455. https://doi.org/10.3897/zookeys.728.20602

Britten HB, Rust RW (1996) Population structure of a sand dune-obligate beetle, Eusattus muricatus, and its implications for dune management. Conservsation Biology 10(2): 647652. https://doi.org/10.1046/j.1523-1739.1996.10020647.x

Brown RW (1956) Composition of scientific words. Smithsonian Books, Washington, D.C. 882pp. ISBN 1-56098-848-7.

Colgan DJ, McLauchlan A, Wilson GDF, Livingston SP, Edgecombe GD, Macaranas J, Cassis G, Gray MR (1998) Histone H3 and U2 snRNA DNA sequences and arthropod molecular evolution. Australian Journal of Zoology 46(5): 419-437.

Doyen JT (1966) The skeletal anatomy of Tenebrio molitor (Coleoptera: Tenebrionidae). Miscellaneous Publications of the Entomological Society of America 5(3):103-150.

Doyen JT, Lawrence JF (1979) Relationships and higher classification of some Tenebrionidae and Zopheridae (Coleoptera). Systematic Entomology 4: 333-377. https://doi.org/10.1111/j.1365-3113.1979.tb00619.x

Eimer T (1898) On orthogenesis: and the impotence of natural selection in species formation. [Translated by Thomas McCormack] 56 pages. The Open Court Publishing Company, Chicago, USA.

Elmore AJ, Mustard JF, Manning SJ (2003) Regional patterns of plant community response to changes in water: Owens Valley, California. Ecological Applications 13(2): 443-460. https://doi.org/10.1890/1051-0761(2003)013[0443:RPOPCR]2.0.CO;2

Galicia D, Leunda PM, Miranda R, Madoz J, Parmenter S (2015) Morphometric contributions to the detection of introgressive hybridization in the endangered owens Tui Chub in California. Transactions of the American Fisheries Society 144(2): 431-442. https://doi.org/10.1080/00028487.2014.996669

Graham MR, Wood DA, Henault JA, Valois ZJ, Cushing PE (2017) Ancient lakes, Pleistocene climates and river avulsions structure the phylogeography of a large but little-known rock scorpion from the Mojave and Sonoran deserts. Biological Journal of the Linnean Society 122(1): 133-146. https://doi.org/10.1093/biolinnean/blx058 
1349

1350

1351

1352

1353

1354

1355

1356

1357

1358

1359

1360

1361

1362

1363

1364

1365

1366

1367

1368

1369

1370

1371

1372

1373

1374

1375

1376

1377

1378

1379

1380

1381

1382

1383

1384

1385

1386

1387

Grehan JR, Ainsworth R (1985) Orthogenesis and evolution. Systematic Zoology 34(2): 174192.

Gries C, Gilbert EE, Franz NM (2014) Symbiota - A virtual platform for creating voucher-based biodiversity information communities. Biodiversity Data Journal 2: e1114.

https://doi.org/10.3897/bdj.2.e1114

Hafner JC, Reddington E, Craig MT (2006) Kangaroo mice (Microdipodops megacephalus) of the Mono Basin: Phylogeography of a peripheral isolate. Journal of Mammalogy 87(6): 1204-1217. https://doi.org/10.1644/06-MAMM-A-067R1.1

Hettinger RD, Roberts LNR, Biewick LRH, Kirschbaum MA (1996) Preliminary investigations of the distribution and resources of coal in the Kaiparowits Plateau, southern Utah. US Geological Survey Open-File Report, 96-539.

Huelsenbeck JP, Crandall KA (1997) Phylogeny estimation and hypothesis testing using maximum likelihood. Annual Review of Ecology and Systematics 28: 437-466. https://doi.org/10.1146/annurev.ecolsys.28.1.437

ICZN (1999) International Code of Zoological Nomenclature, Fourth Edition. International Trust for Zoological Nomenclature, c/o The Natural History Museum, London.

ICZN (2012) Amendment of Articles 8, 9, 10, 21 and 78 of the International Code of Zoological Nomenclature to expand and refine methods of publication. Zookeys 219: 1-10. https://doi.org/10.3897/zookeys.219.3944

Iwan D (2001) A comparative study of male genitalia in opatrinae sensu Medvedev (1968) (Coleoptera: Tenebrionidae), with notes on the tribal classification. Part 1. Annales Zoologici 51(3): 351-390.

Iwan D, Kamiński MJ (2016) Toward a natural classification of opatrine darkling beetles: comparative study of female terminalia. Zoomorphology 135(4): 453-485. https://doi.org/10.1007/s00435-016-0328-5

Johnston MA (2015) A checklist and new species of Eleodes Eschscholtz (Coleoptera: Tenebrionidae) pertaining to the Subgenus Promus Leconte, with a key to United States species. The Coleopterists Bulletin 69: 11-19. https://doi.org/10.1649/0010-065X-69.1.11 
1388

1389

1390

1391

1392

1393

1394

1395

1396

1397

1398

1399

1400

1401

1402

1403

1404

1405

1406

1407

1408

1409

1410

1411

1412

1413

1414

1415

1416

1417

1418

1419

1420

1421

1422

1423

1424

1425

Johnston MA (2016) Redefinition of the Eleodes Eschscholtz subgenera Tricheleodes Blaisdell and Pseudeleodes Blaisdell, with the description of a new species (Coleoptera: Tenebrionidae). Annales Zoologici (Warszawa) 66(4): 665-679. https://doi.org/10.3161/00034541ANZ2016.66.4.018

Johnston MA (2018) Diversity and distribution of the desert stink beetles: Systematics of the Amphidorini LeConte, 1862 (Coleoptera: Tenebrionidae). Ph. D. thesis, Arizona State University, 226pp. https://repository.asu.edu/items/51646

Johnston MA, Aalbu R, Franz N (2018) An updated checklist of the Tenebrionidae sec. Bousquet et al. 2018 of the Algodones Dunes of California, with comments on checklist data practices. Biodiversity Data Journal 6: e24927. https://doi.org/10.3897/BDJ.6.e24927

Johnston MA, Fleming D, Franz N, Smith A (2015) Amphidorini Leconte (Coleoptera: Tenebrionidae) of Arizona: Keys and species accounts. The Coleopterists Bulletin 69: 2754. https://doi.org/10.1649/0010-065x-69.mo4.27

Jones CH, Farmer GL, Unruh J (2004) Tectonics of Pliocene removal of lithosphere of the Sierra Nevada, California. Geological Society of America Bulletin 116(11-12): 1408-1422. https://doi.org/10.1130/B25397.1

Kamiński MJ, Kanda K, Lumen R, Smith AD, Iwan D (2018) Molecular phylogeny of Pedinini (Coleoptera: Tenebrionidae) and its implications for higher-level classification. Zoological Journal of the Linnean Society zly033. https://doi.org/10.1093/zoolinnean/zly033

Kanda K (2017) Phylogenetic studies in Tenebrionidae (Coleoptera) and related families. Ph. D. thesis, Oregon State University, $265 \mathrm{pp}$.

https://ir.library.oregonstate.edu/concern/graduate_thesis_or_dissertations/qj72pd34k

Katoh K, Standley DM (2013) MAFFT multiple sequence alignment software version 7: Improvements in performance and usability. Molecular Biology and Evolution 30(4): 772 780. http://doi.org/10.1093/molbev/mst010

Kergoat GJ, Bouchard P, Clamens AL, Abbate JL, Jourdan H, Jabbour-Zahab R, Genson G, Soldati L, Condamine FL (2014) Cretaceous environmental changes let to high extinction rates in a hyperdiverse beetle family. BMC Evolutionary Biology 14(1): 220. https://doi.org/10.1186/s12862-014-0220-1 
1426 Koehler PA, Anderson RS (1995) Thirty thousand years of vegetation changes in the Alabama

1427

1428

1429

1430

1431

1432

1433

1434

1435

1436

1437

1438

1439

1440

1441

1442

1443

1444

1445

1446

1447

1448

1449

1450

1451

1452

1453

1454

1455

1456

1457

1458

1459

1460

1461

1462

1463

1464

1465

Hills, Owens Valley, California. Quaternary Research 43(2): 238-248. https://doi.org/10.1006/qres.1995.1024

Kulzer H (1960) Einige neue Tenebrioniden (Col.) (20. Beitrag zur Kenntnis der Tenebrioniden). Entomologische Arbeiten aus dem Museum G. Frey 11: 304-317.

Kumar S, Stecher G, Tamura K (2016). MEGA7: Molecular evolutionary genetics analysis version 7.0 for bigger datasets. Molecular Biology and Evolution 33:1870-1874. https://doi.org/10.1093/molbev/msw054

Lancaster N, Baker S, Bacon S, McCarley-Holder G (2015) Owens Lake dune fields: Composition, sources of sand, and transport pathways. CATENA 134:41-49. https://doi.org/10.1016/j.catena.2015.01.003

Lanfear R, Calcott B, Ho SY, Guindon S (2012). PartitionFinder: combined selection of partitioning schemes and substitution models for phylogenetic analyses. Molecular Biology and Evolution 29(6), 1695-1701. https://doi.org/10.1093/molbev/mss020

Lanfear R, Frandsen PB, Wright AM, Senfeld T, Calcott B (2016) PartitionFinder 2: new methods for selecting partitioned models of evolution for molecular and morphological phylogenetic analyses. Molecular Biology and Evolution 34(1): 772-773.

https://doi.org/10.1093/molbev/msw260

La Rivers I (1943) A new Trogloderus from Nevada, with a key to the known species (Coleoptera: Tenebrionidae). Annals of the Entomological Society of America 35 [1942]: 435-440. https://doi.org/10.1093/aesa/35.4.435

La Rivers I (1946) On the genus Trogloderus LeConte (Coleoptera: Tenebrionidae). Entomological News 57: 35-44.

LeConte JL (1879) New Coleoptera. The North American Entomologist 1[1879-80]: 1-5.

Lee J, Stockli DF, Owen LA, Finkel RC, Kislitsyn R (2009) Exhumation of the Inyo Mountains, California: Implications for the timing of extension along the western boundary of the Basin and Range Province and distribution of dextral fault slip rates across the eastern California shear zone. Tectonics 28 TC1001 https://doi.org/10.1029/2008TC002295

Macey JR (1986) The biogeography of a herpetofaunal transition between the Great Basin and Mojave deserts. In Hall CA, Young DJ (eds.), Natural history of the White-Inyo Range,

PeerJ reviewing PDF | (2019:06:38531:1:1:NEW 26 Sep 2019) 
1466

1467

1468

1469

1470

1471

1472

1473

1474

1475

1476

1477

1478

1479

1480

1481

1482

1483

1484

1485

1486

1487

1488

1489

1490

1491

1492

1493

1494

1495

1496

1497

1498

1499

1500

1501

1502

1503

eastern California and western Nevada, and high altitude physiology, pg. 119-128. University of California White Mountain Research Station Symposium, August 23-25, 1985, Bishop, Calif. Vol. 1.

Maddison DR (2008) Systematics of the North American beetle subgenus Pseudoperyphus (Coleoptera: Carabidae: Bembidion) based upon morphological, chromosomal, and molecular data. Annals of Carnegie Museum 77: 147-193. https://doi.org/10.2992/00974463-77.1.147

Maddison WP, Maddison DR (2018) Mesquite: a modular system for evolutionary analysis. Version 3.51 http://www.mesquiteproject.org.

Matzke, N.J. (2013) Probabilistic historical biogeography:new models for founder-event speciation, imperfect detection, and fossils allow improved accuracy and model-testing. Frontiers of Biogeography 5: 242-248. https://doi.org/10.21425/F5FBG19694

Matzke NJ (2014) Model selection in historical biogeography reveals that founder-event speciation is a crucial process in island clades. Systematic Biology 63(6): 951-970. https://doi.org/10.1093/sysbio/syu056

Mayr E (1982) The growth of biological thought: Diversity, evolution, and inheritance. The Belknap Press of Harvard University Press, Cambridge, Massachusetts.

McNee WR, Wood DL, Storer AJ (2000) Pre-emergence feeding in bark beetles (Coleoptera: Scolytidae). Environmental Entomology 29(3): 495-501. https://doi.org/10.1603/0046225X-29.3.495

Papp CS (1961) A new Trogloderus from the Aeolian saline dunes of southern California (Notes on North American Coleoptera, No. 15). Bulletin of the Southern California Academy of Sciences 60: 32-36.

Papp CD, Pierce HD (1960) Ecological remarks on some tenebrionids connected with stored animal food in the Mojave Desert, California. Journal of the Kansas Entomological Society 33: 154-156.

Pavlik BM (1989) Phytogeography of sand dunes in the Great Basin and Mojave deserts. Journal of Biogeography 16(3): 227-238. https://doi.org/10.2307/2845259 
1504 Polyak V, Hill C, Asmerom Y (2008) Age and evolution of the Grand Canyon revealed by U-Pb

1505

1506

1507

1508

1509

1510

1511

1512

1513

1514

1515

1516

1517

1518

1519

1520

1521

1522

1523

1524

1525

1526

1527

1528

1529

1530

1531

1532

1533

1534

1535

1536

1537

1538

1539

1540

1541

1542 dating of water table-type speleothems. Science 319: 1377-1380.

https://doi.org/10.1126/science. 1151248

R Core Team (2018) R: A language and environment for statistical computing. R Foundation for Statistical Computing, Vienna, Austria. URL https://www.R-project.org/

Rambaut A, Drummond AJ, Xie D, Baele G and Suchard MA (2018) Posterior summarisation in Bayesian phylogenetics using Tracer 1.7. Systematic Biology 67(5): 901-904. https://doi.org/10.1093/sysbio/syy032

Reveal JL (1979) Biogeography of the Intermountain Region: A speculative appraisal. Mentzelia 4: 1-92.

Roberts EM (2007) Facies architecture and depositional environments of the Upper Cretaceous Kaiparowits Formation, southern Utah. Sedimentary Geology 197(3-4): 207-233. https://doi.org/10.1016/j.sedgeo.2006.10.001

Ronquist F, Huelsenbeck JP (2003) MRBAYES 3: Bayesian phylogenetic inference under mixed models. Bioinformatics 19(12): 1572-1574. https://doi.org/10.1093/bioinformatics/btg180

Sampson SD, Loewen MA, Farke AA, Roberts EM, Forster CA, Smith JA, Titus AL (2010). New horned dinosaurs from Utah provide evidence for intracontinental dinosaur endemism. PLoS One, 5(9), e12292. https://doi.org/10.1371/journal.pone.0012292

Shreve F (1942) The desert vegetation of North America. Botanical Review 8 (4): 195-246. https://doi.org/10.1007/BF02882228

Simon C, Frati F, Beckenback A, Crespi B, Liu H, Flook P (1994) Evolution, weighting, and phylogenetic utility of mitochondrial gene sequences and a compilation of conserved polymerase chain reaction primers. Annals of the Entomological Society of America 87(6): 651-701. https://doi.org/10.1093/aesa/87.6.651

Somerby RE (1972) Systematics of Eleodes (Blapylis) with a revision of the caseyi group using taximetric methods (Coleoptera: Tenebrionidae). Ph.D. Thesis, University of California, Riverside. $x x v+441$ pp.

Spencer JE, Patchett PJ, Pearthree PA, House PK, Sarna-Wojcicki AM, Wan E, Roskowski JA, Faulds JE (2013) Review and analysis of the age and origin of the Pliocene Bouse

PeerJ reviewing PDF | (2019:06:38531:1:1:NEW 26 Sep 2019) 
1543

1544

1545

1546

1547

1548

1549

1550

1551

1552

1553

1554

1555

1556

1557

1558

1559

1560

1561

1562

1563

1564

1565

1566

1567

1568

1569

1570

1571

1572

1573

1574

1575

1576

1577

1578

1579

1580

1581

Formation, lower Colorado River Valley, southwestern USA. Geosphere 9(3):444-459. https://doi.org/10.1130/GES00896.1

Stamatakis A (2014) RAxML version 8: a tool for phylogenetic analysis and post-analysis of large phylogenies. Bioinformatics 30(9):1312-1313. https://doi.org/10.1093/bioinformatics/btu033

Tamura K, Battistuzzi FU, Billing-Ross P, Murillo O, Filipski A, Kumar S (2012). Estimating Divergence Times in Large Molecular Phylogenies. Proceedings of the National Academy of Sciences 109:19333-19338. https://doi.org/10.1073/pnas.1213199109

Tanner VM, Packham WA (1965) Tenebrionidae beetles of the Nevada test site. Brigham Young University Science Bulletin (Biological Series) 6(1): 1-44.

Triplehorn CA, Thomas DB (2012) Studies in the genus Eleodes Eschscholtz with a revision of the subgenus Melaneleodes Blaisdell and Omegeleodes, new subgenus (Coleoptera: Tenebrionidae: Eleodini). Transactions of the American Entomological Society 137 [2011]: 251-281. URL: https://www.jstor.org/stable/41550034

Van Dam MH, Matzke NJ (2016) Evaluating the influence of connectivity and distance on biogeographical patterns in the south-western deserts of North America. Journal of Biogeography 43(8): 1514-1532. https://doi.org/10.1111/jbi.12727

Van der Auwera G, Chapelle S, De Wachter R (1994) Structure of the large ribosomal subunit RNA of Phytophthora megasperma, and phylogeny of the oomycetes. FEBS Letters 338: 133-136. https://doi.org/10.1016/0014-5793(94)80350-1

Whiting MF (2002) Mecoptera is paraphyletic: multiple genes and phylogeny of Mecoptera and Siophonaptera. Zoologica Scripta 31: 93-104. https://doi.org/10.1046/j.03003256.2001.00095.x

Wild AL, Maddison DR (2008) Evaluating nuclear protein-coding genes for phylogenetic utility in beetles. Molecular Phylogenetics and Evolution 48: 877-891. https://doi.org/10.1016/j.ympev.2008.05.023

Wiley EO, Mayden RL (2000) The evolutionary species concept. In Wheeler QD, Meier R Eds. Species Concepts and Phylogenetic Theory. Columbia University Press, New York. Pp 7092. 
1582

1583

1584

1585

1586

1587

1588

1589

1590

1591

1592

1593

1594

1595

1596

1597

1598

1599

1600

1601

1602

1603

1604

1605

1606

1607

1608

1609

1610

1611

1612

1613

1614

1615

1616

1617

1618

1619

1620

1621

Will K, Madan R, Hsu HH (2017) Additions to the knowledge of Nevada carabid beetles (Coleoptera: Carabidae) and a preliminary list of carabids from the Great Basin National Park. Biodiversity Data Journal 5: e12250. https://doi.org/10.3897/BDJ.5.e12250

Wilson JS, Pitts JP (2010) Illuminating the lack of consensus among descriptions of earth history data in the North American deserts: A resource for biologists. Progress in Physical Geography: Earth and Environment 34(4): 419-441. https://doi.org/10.1177\%2F0309133310363991

Zhang G, Basharat U, Matzke N, Franz NM (2017) Model selection in statistical historical biogeography of Neotropical insects - The Exophthalmus genus complex (Curculionidae: Entiminae). Molecular Phylogenetics and Evolution 109: 226-239. https://doi.org/10.1016/j.ympev.2016.12.039

Figure 1. Collection localities of Trogloderus molecular vouchers and biogeographic regions. Map created in qgis utilizing Google Earth imagery. Map data (C2019 Google, SIO, NOAA, U.S. Navy, NGA, GEBCO.

Figure 2. Trogloderus external morphology. A. Dorsal habitus, Trogloderus vandykei La Rivers. B. Ventral habitus, Trogloderus vandykei La Rivers. ad - abdominal depression, dc - elytral discal costa, fs - femoral spine, $\mathrm{pf}$ - pronotal foveae, $\mathrm{pg}$ - prosternal groove, $\mathrm{pp}$ - prosternal process, sc - elytral sutural costa.

Figure 3. Trogloderus mouthparts. Dissected from MAJC0004230, T. major Johnston n.sp. A. Right mandible, ventral view. B. Left mandible, dorsal view. C. Right maxilla, ventral view. D. Left maxilla, dorsal view. E. Labium, ventral view.

Figure 4. Trogloderus internal morphology. A. Pterothorax venter, dorsal internal view; Metendosternite and right mesosternal apophysis highlighted; Dissected from MAJC0004244, $T$. warneri Johnston n.sp. B. Defensive glands and abdominal ventrite V, dorsal internal view; Dissected from MAJC0004231, T. arcanus Johnston n.sp.

Figure 5. Trogloderus terminalia. A. Female terminalia, dorsal view, showing bursa-derived spermatheca; T. vandykei La Rivers. B. Female terminalia, ventral view, showing bursa copulatrix and oviduct; Dissected from MAJC0004243, T. major Johnston n.sp. C. Male adeagus, ventral view; clavae and penis highlighted; T. vandykei La Rivers.

Figure 6. Trogloderus species, dorsal habitus. A. T. tuberculatus Blaisdell (non-type). B. T. verpus Johnston n.sp. (holotype). C. T. warneri Johnston n.sp. (holotype). D. T. skillmani 
1622 Johnston n.sp. (holotype). E. T. arcanus Johnston n.sp. (holotype). F. T. costatus LeConte (non1623 type). G. T. nevadus La Rivers (non-type). H. T. major Johnston n.sp. (holotype). I. T. kandai 1624 Johnston n.sp. (holotype).

1625

1626

1627

1628

1629

1630

1631

1632

1633

1634

1635

1636

1637

1638

1639

1640

1641

1642

1643

1644

1645

1646

1647

1648

1649

1650

1651

1652

1653

1654
Figure 7. Trogloderus species, adeagus dorsal view. A. T. arcanus Johnston n.sp. B. T. costatus LeConte. C. T. kandai Johnston n.sp. D. T. major Johnston n.sp. E. T. nevadus La Rivers. F. T. skillmani Johnston n.sp. G. T. tuberculatus Blaisdell. H. T. vandykei La Rivers. I. T. verpus Johnston n.sp. J. T. warneri Johnston n.sp.

Figure 8. Distribution map, Trogloderus arcanus Johnston n.sp., T. costatus LeConte, T. kandai Johnston n.sp. Map data @2019 Google, SIO, NOAA, U.S. Navy, NGA, GEBCO.

Figure 9. Distribution map, Trogloderus major Johnston n.sp., T. nevadus La Rivers, T. skillmani Johnston n.sp. Map data @2019 Google, SIO, NOAA, U.S. Navy, NGA, GEBCO.

Figure 10. Distribution map, Trogloderus tuberculatus Blaisdell, T. vandykei La Rivers, $T$. verpus Johnston n.sp., T. warneri Johnston n.sp. Map data @2019 Google, SIO, NOAA, U.S. Navy, NGA, GEBCO.

Figure 11. Phylogenetic reconstruction of Trogloderus. Tree shown is from the MrBayes analysis, numbers above branches are posterior probabilities, numbers below the branches arethe corresponding RAxML bootstrap support values. Outgroup specimens belonging to the genus Eleodes are highlighted. The monophyletic Trogloderus is indicated by a box, and the reciprocally monophyletic Reticulate-pronotum and Tuberculate-pronotum clades are indicated by vertical bars.

Figure 12. Phylogenetic dating estimates for Trogloderus. A. Timetree generated from BEAST showing inferred median node ages. B. Same showing $95 \%$ highest posterior density for node ages. C. Timetree generated from RelTime showing inferred median node ages. D. Same showing 95\% confidence intervals for node ages.

Figure 13. Historical biogeographic estimation of Trogloderus. Generated from BioGeoBEARS using the $\mathrm{DEC}+\mathrm{J}$ model. Nodes colored by inferred most likely biogeographic region. 
Figure 1

Collection localities of Trogloderus molecular vouchers and biogeographic regions. Map created in qgis utilizing Google Earth imagery. Map data @ 2019 Google, SIO, NOAA, U.S. Navy, NGA, GEBCO.

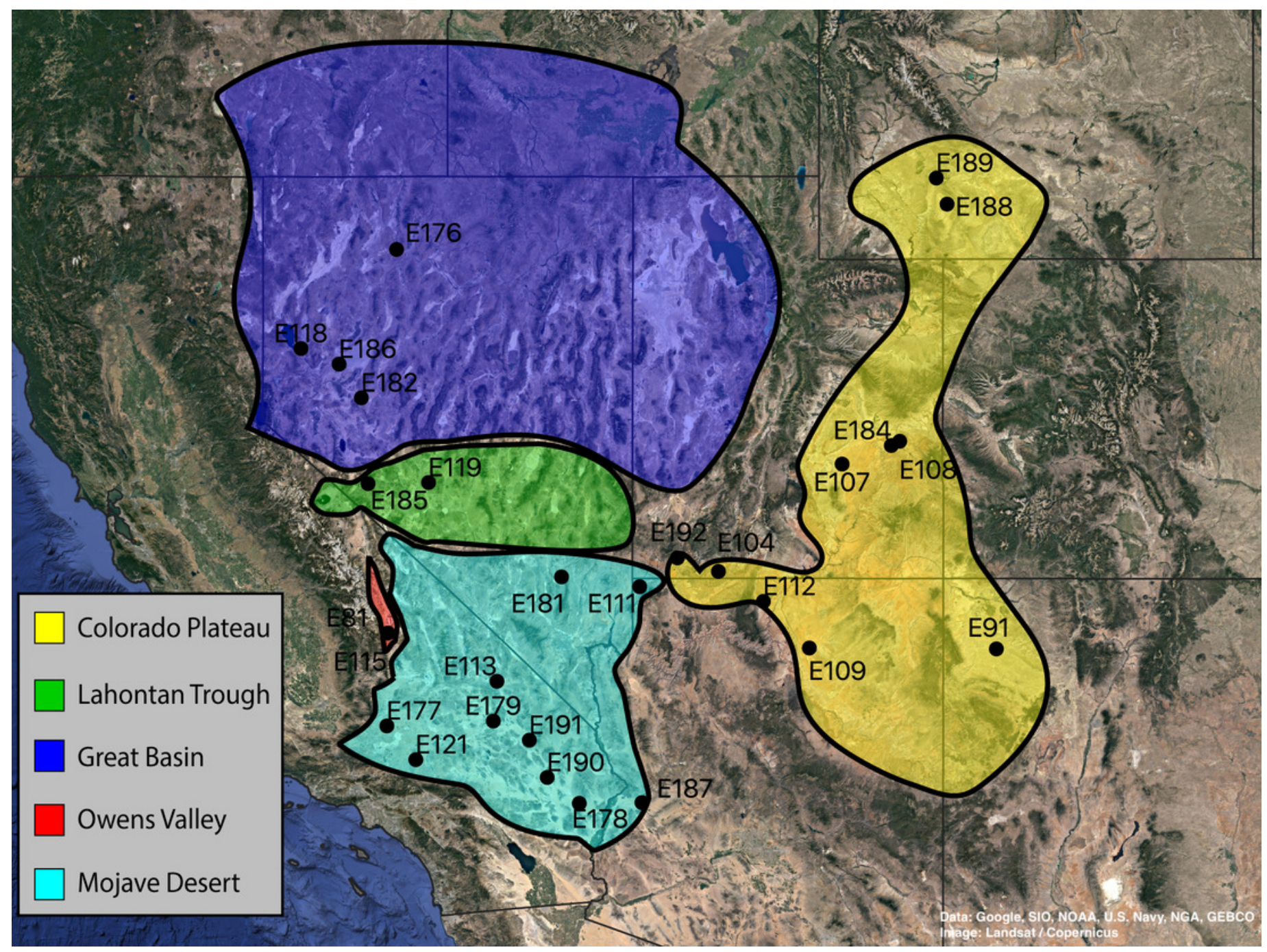


Figure 2

Trogloderus external morphology.

(A) Dorsal habitus, Trogloderus vandykei La Rivers. (B) Ventral habitus, Trogloderus

vandykei La Rivers. ad - abdominal depression, dc - elytral discal costa, fs - femoral spine, pf - pronotal foveae, pg - prosternal groove, pp - prosternal process, sc - elytral sutural costa. 


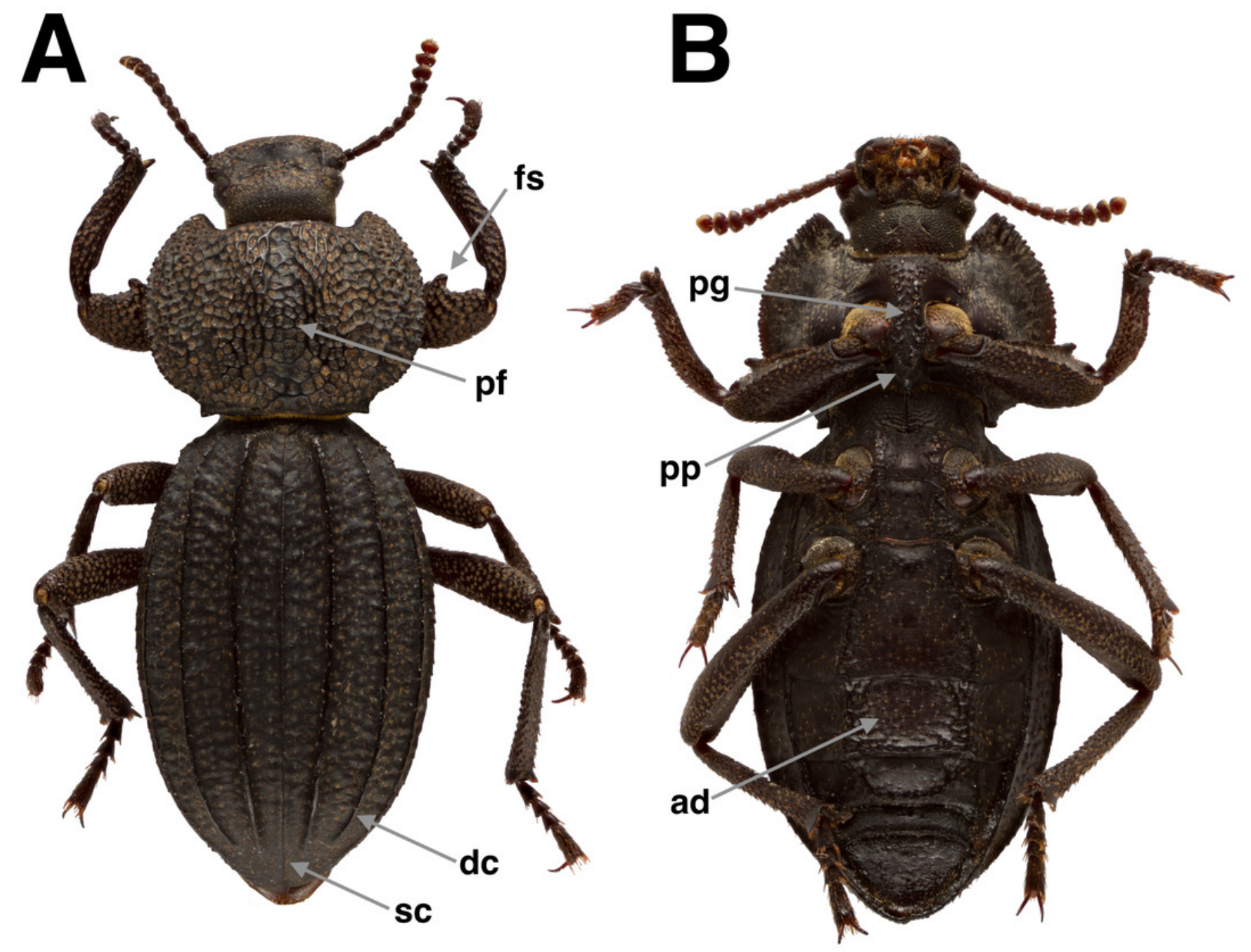




\section{Figure 3}

Trogloderus mouthparts.

Dissected from MAJC0004230, T. major Johnston n.sp. (A) Right mandible, ventral view. (B) Left mandible, dorsal view. (C) Right maxilla, ventral view. (D) Left maxilla, dorsal view. (E) Labium, ventral view.

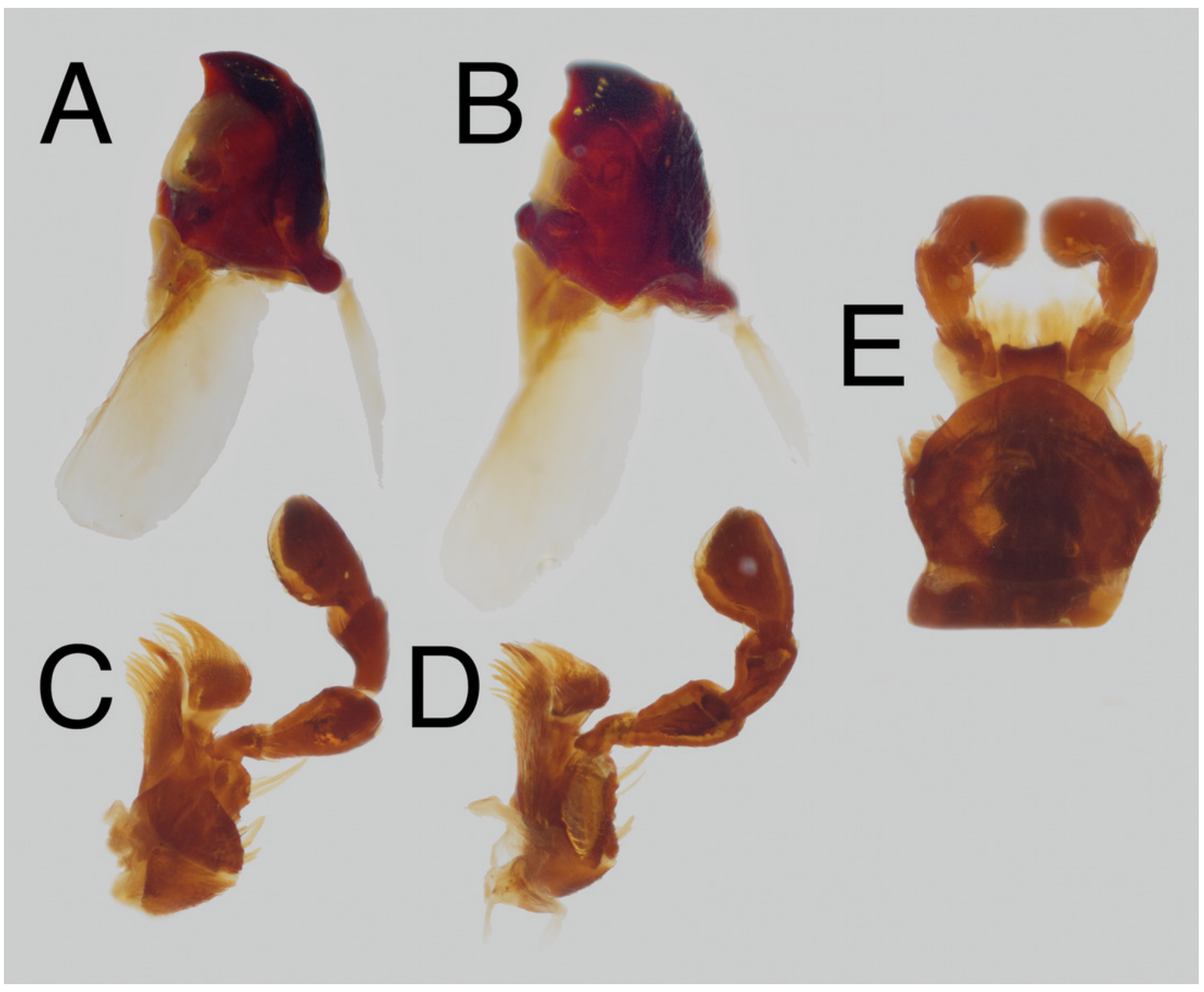




\section{Figure 4}

Trogloderus internal morphology.

(A) Pterothorax venter, dorsal internal view; Metendosternite and right mesosternal apophysis highlighted; Dissected from MAJC0004244, T. warneri Johnston n.sp. (B) Defensive glands and abdominal ventrite V, dorsal internal view; Dissected from MAJC0004231, $T$. arcanus Johnston n.sp.

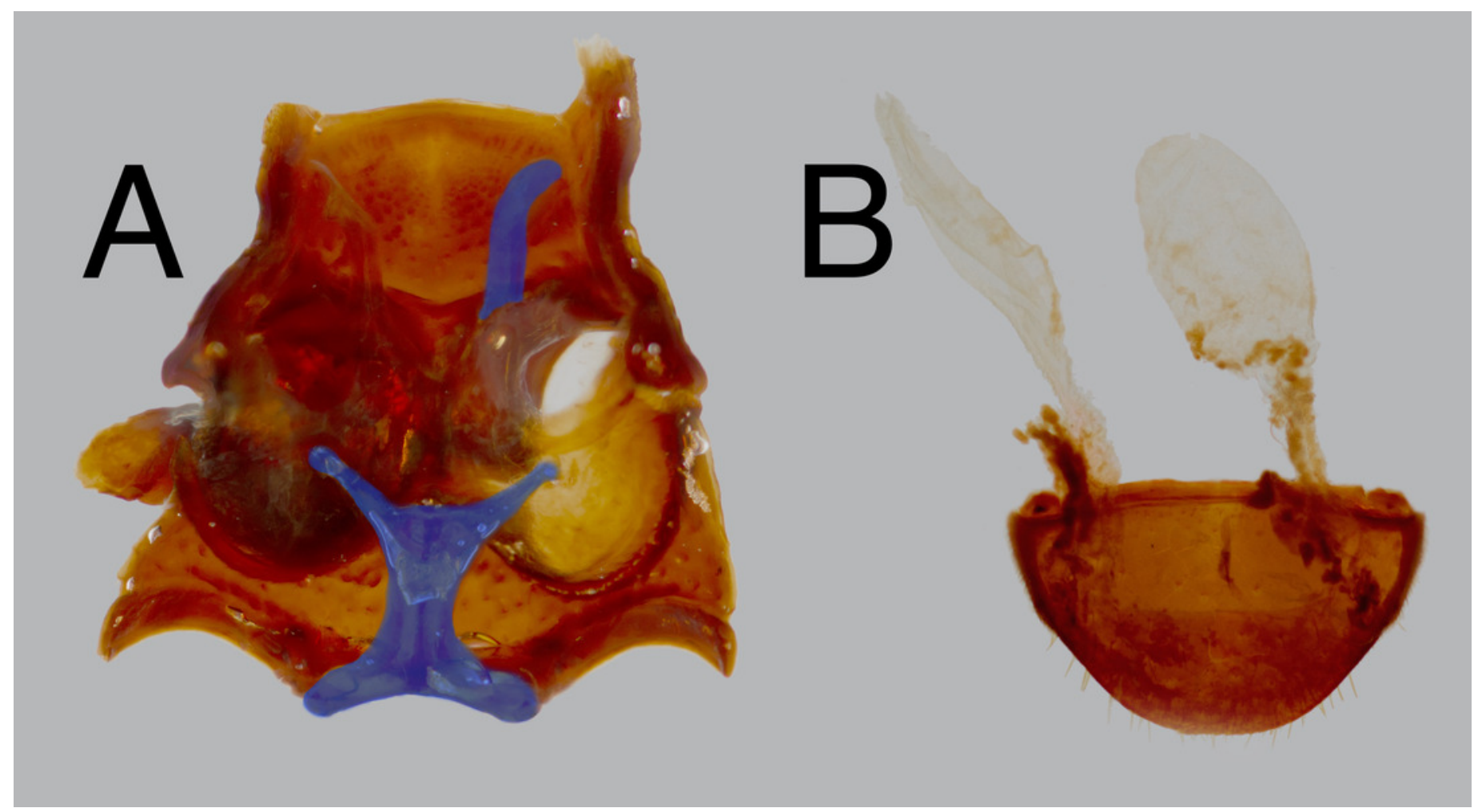




\section{Figure 5}

Trogloderus terminalia.

(A) Female terminalia, dorsal view, showing bursa-derived spermatheca; T. vandykei La

Rivers. (B) Female terminalia, ventral view, showing bursa copulatrix and oviduct; Dissected from MAJC0004243, T. major Johnston n.sp. (C) Male adeagus, ventral view; clavae and penis highlighted; $T$. vandykei La Rivers.
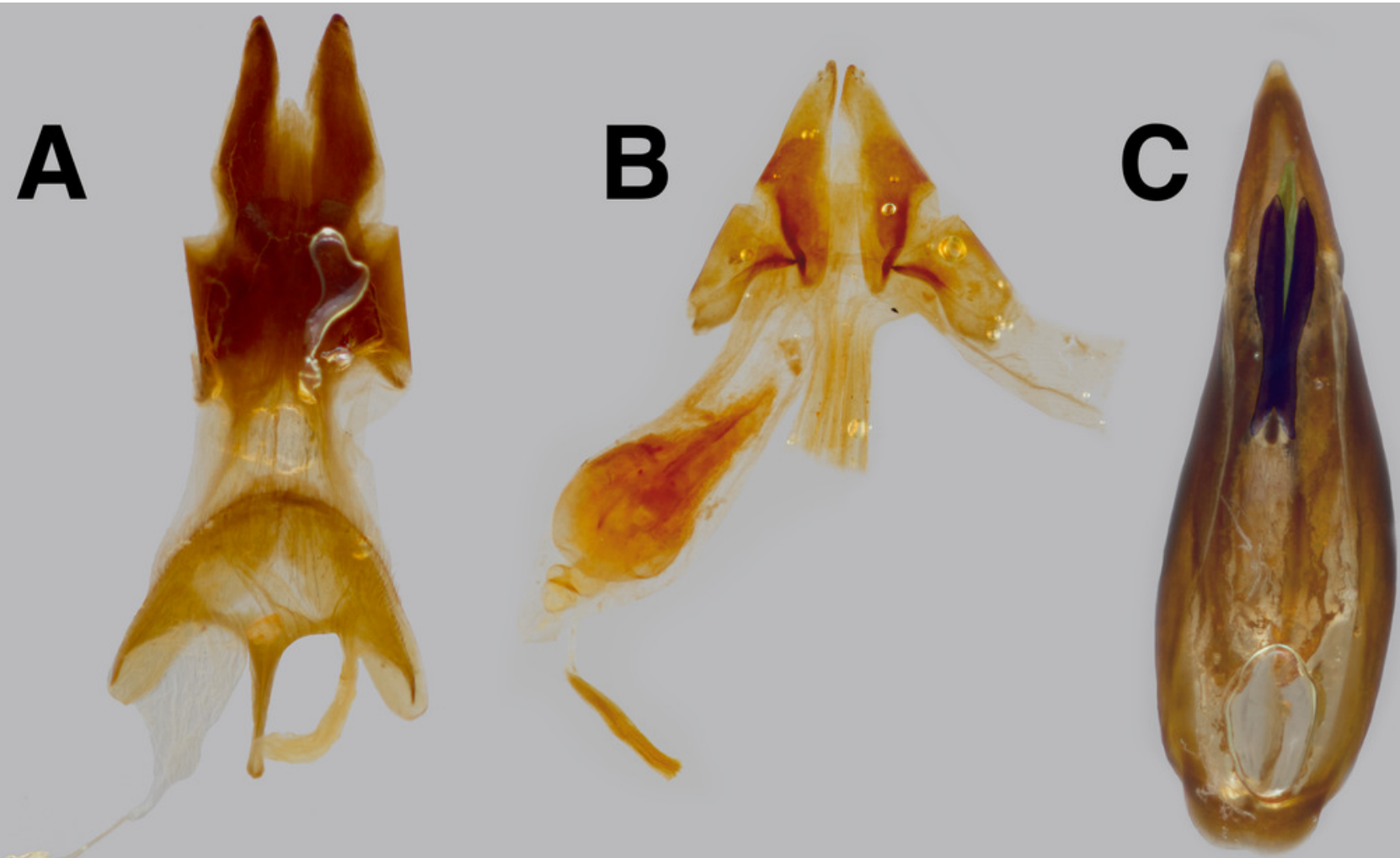


\section{Figure 6}

Trogloderus species, dorsal habitus.

(A) T. tuberculatus Blaisdell (non-type). (B) T. verpus Johnston n.sp. (holotype). (C) T. warneri Johnston n.sp. (holotype). (D) T. skillmani Johnston n.sp. (holotype). (E) T. arcanus Johnston n.sp. (holotype). (F) T. costatus LeConte (non-type). (G) T. nevadus La Rivers (nontype). (H) T. major Johnston n.sp. (holotype). (I) T. kandai Johnston n.sp. (holotype). 

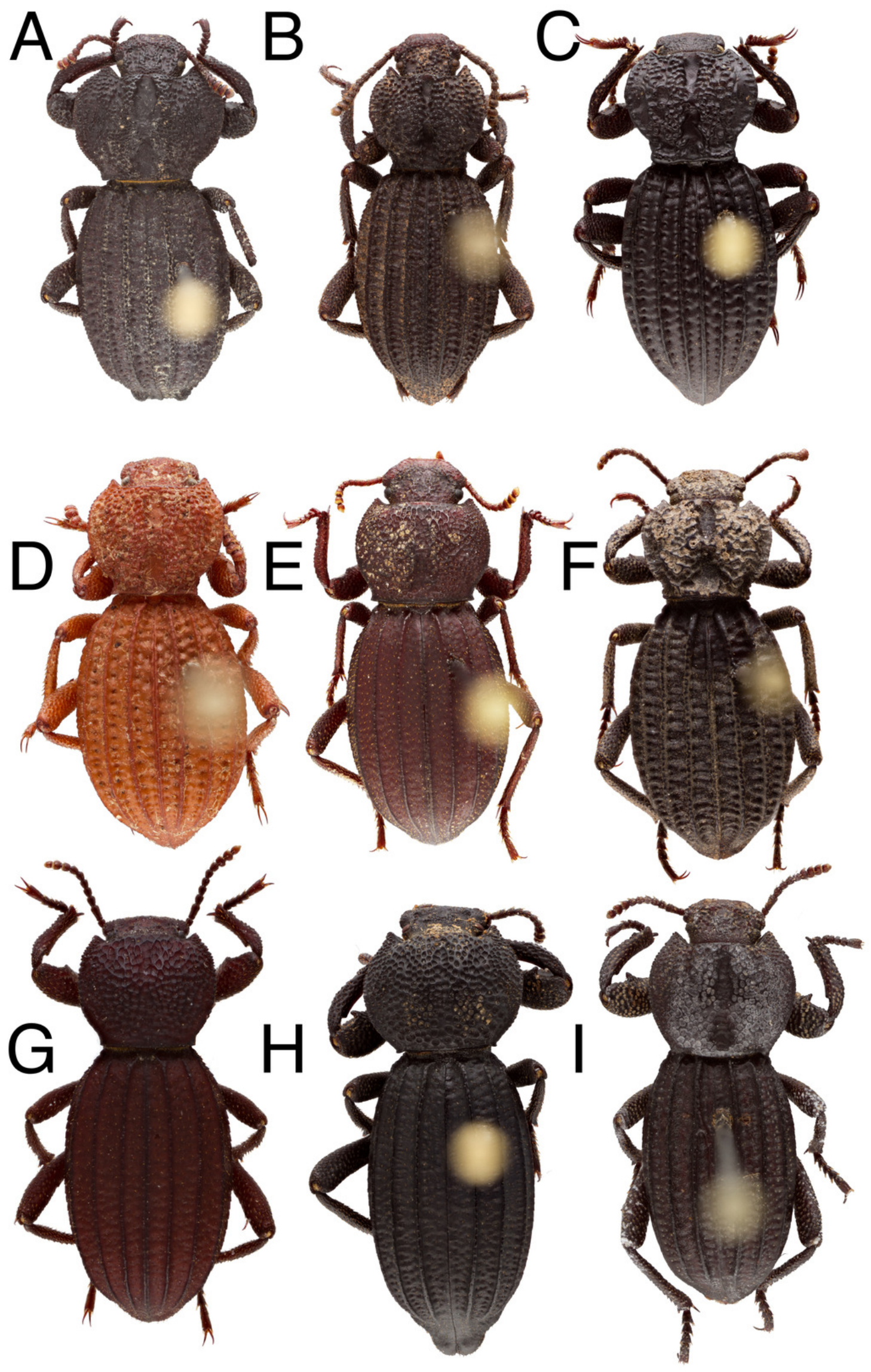
Figure 7

Trogloderus species, adeagus dorsal view.

(A) T. arcanus Johnston n.sp. (B) T. costatus LeConte. (C) T. kandai Johnston n.sp. (D) T. major Johnston n.sp. (E) T. nevadus La Rivers. (F) T. skillmani Johnston n.sp. (G) T. tuberculatus Blaisdell. (H) T. vandykei La Rivers. (I) T. verpus Johnston n.sp. (J) T. warneri Johnston n.sp. 

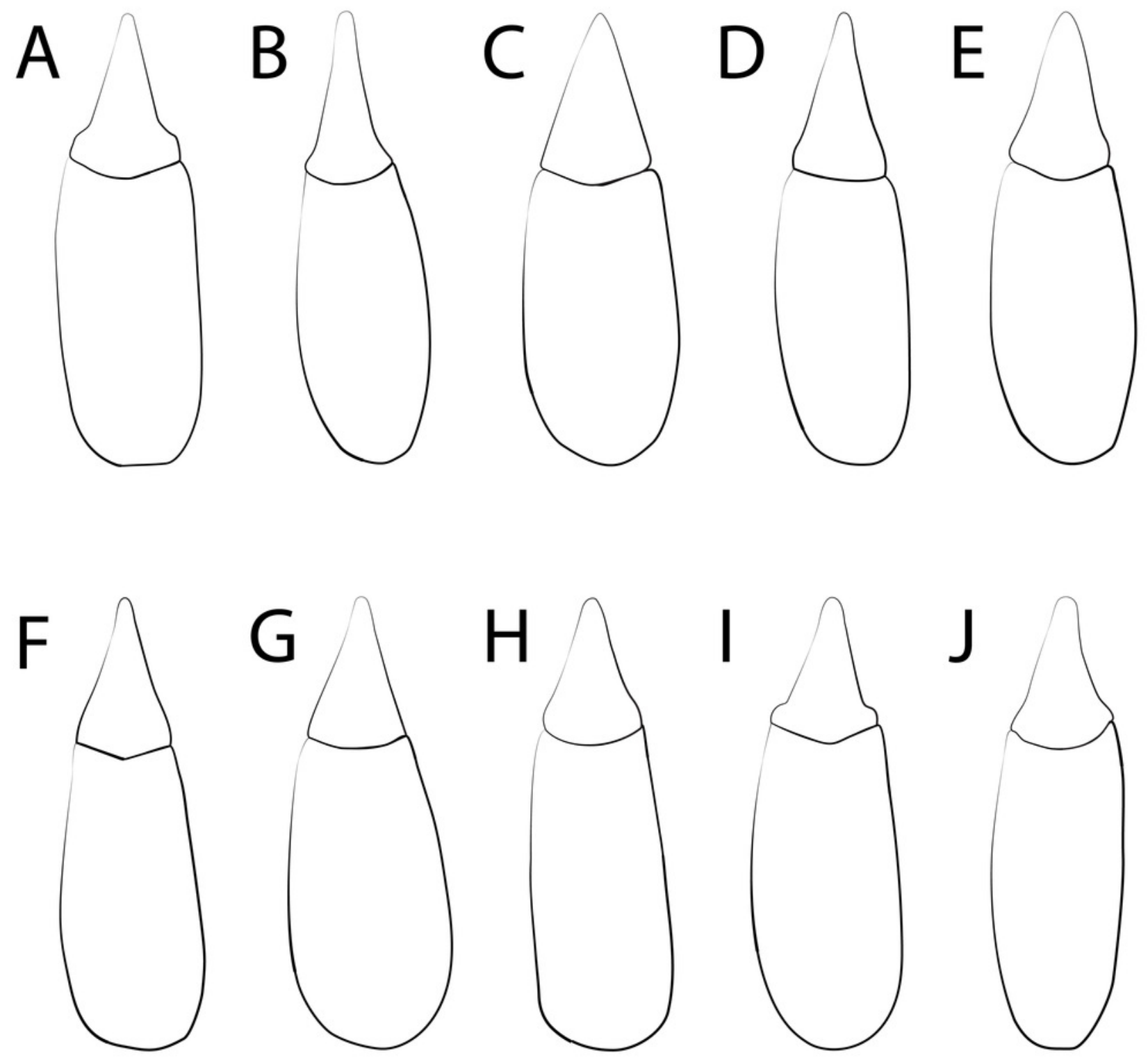
Figure 8

Distribution map, Trogloderus arcanus Johnston n.sp., T. costatus LeConte, T. kandai Johnston n.sp. Map data $\odot 2019$ Google, SIO, NOAA, U.S. Navy, NGA, GEBCO.

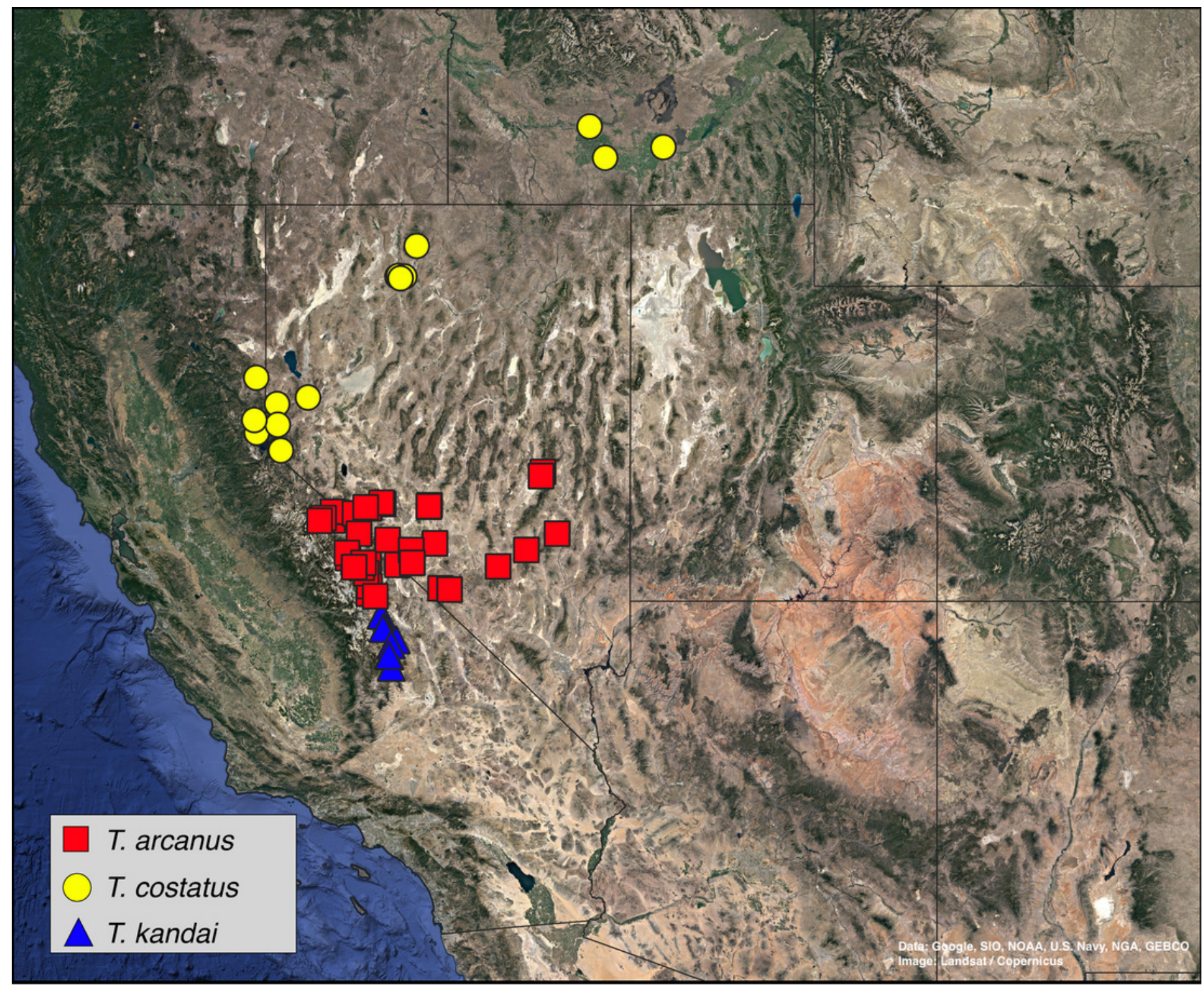


Figure 9

Distribution map, Trogloderus major Johnston n.sp., T. nevadus La Rivers, T. skillmani Johnston n.sp. Map data $\odot 2019$ Google, SIO, NOAA, U.S. Navy, NGA, GEBCO.

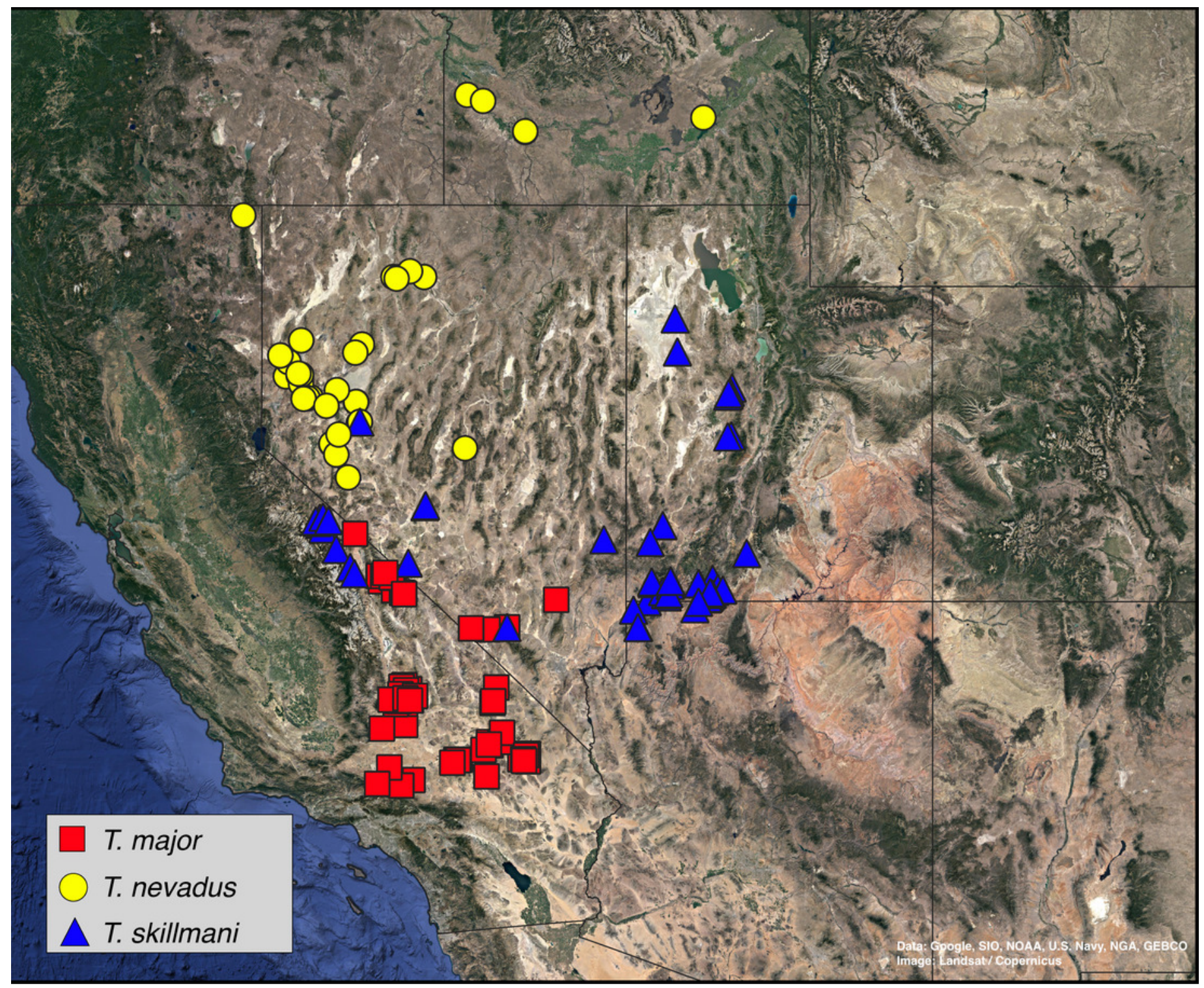




\section{Figure 10}

Distribution map, Trogloderus tuberculatus Blaisdell, $T$. vandykei La Rivers, $T$. verpus Johnston n.sp., T. warneri Johnston n.sp. Map data @ 2019 Google, SIO, NOAA, U.S. Navy, NGA, GEBCO.

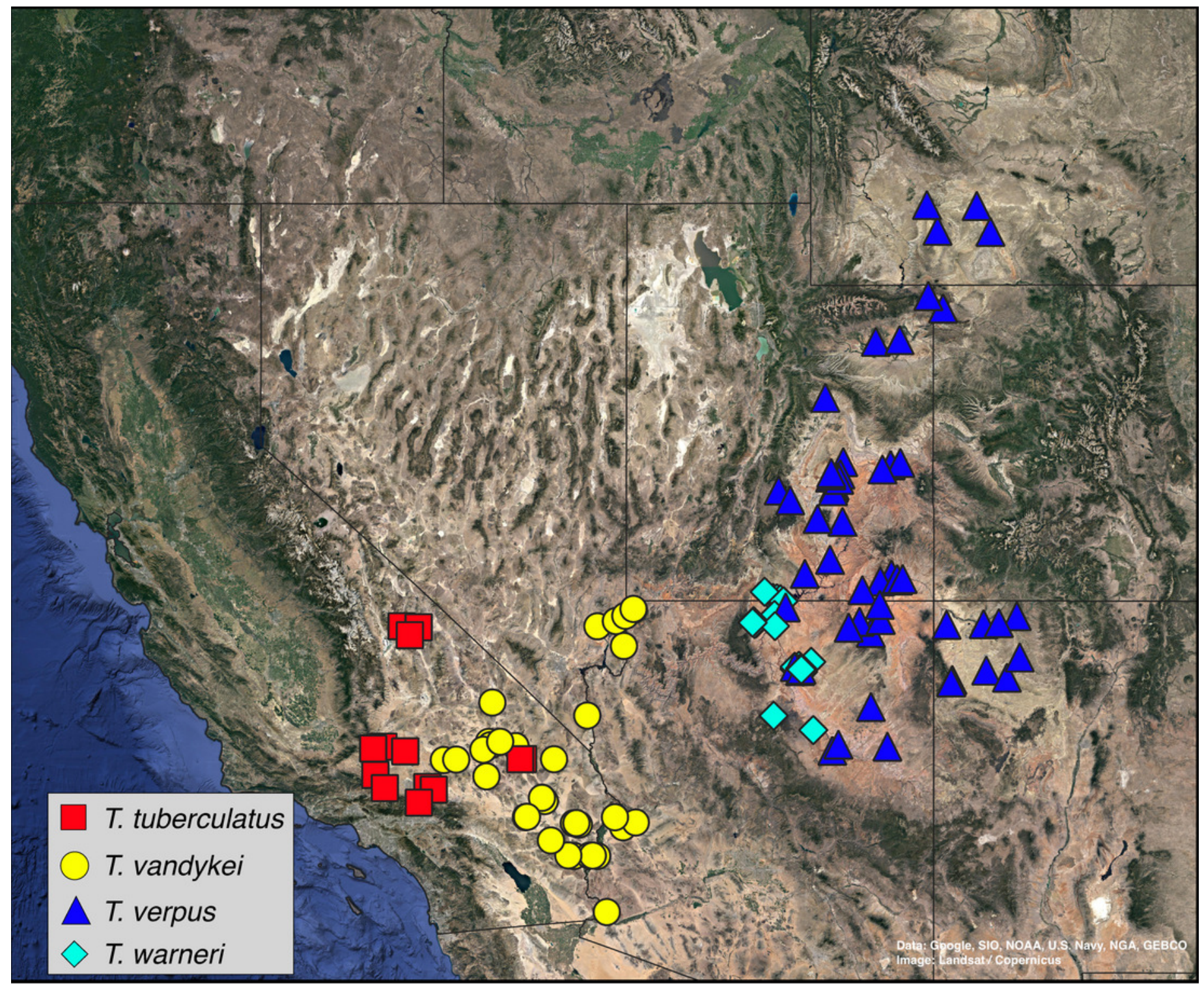




\section{Figure 11}

Phylogenetic reconstruction of Trogloderus.

Tree shown is from the MrBayes analysis, numbers above branches are posterior probabilities, numbers below the branches arethe corresponding RAxML bootstrap support values. Outgroup specimens belonging to the genus Eleodes are highlighted. The monophyletic Trogloderus is indicated by a box, and the reciprocally monophyletic Reticulate-pronotum and Tuberculate-pronotum clades are indicated by vertical bars. 


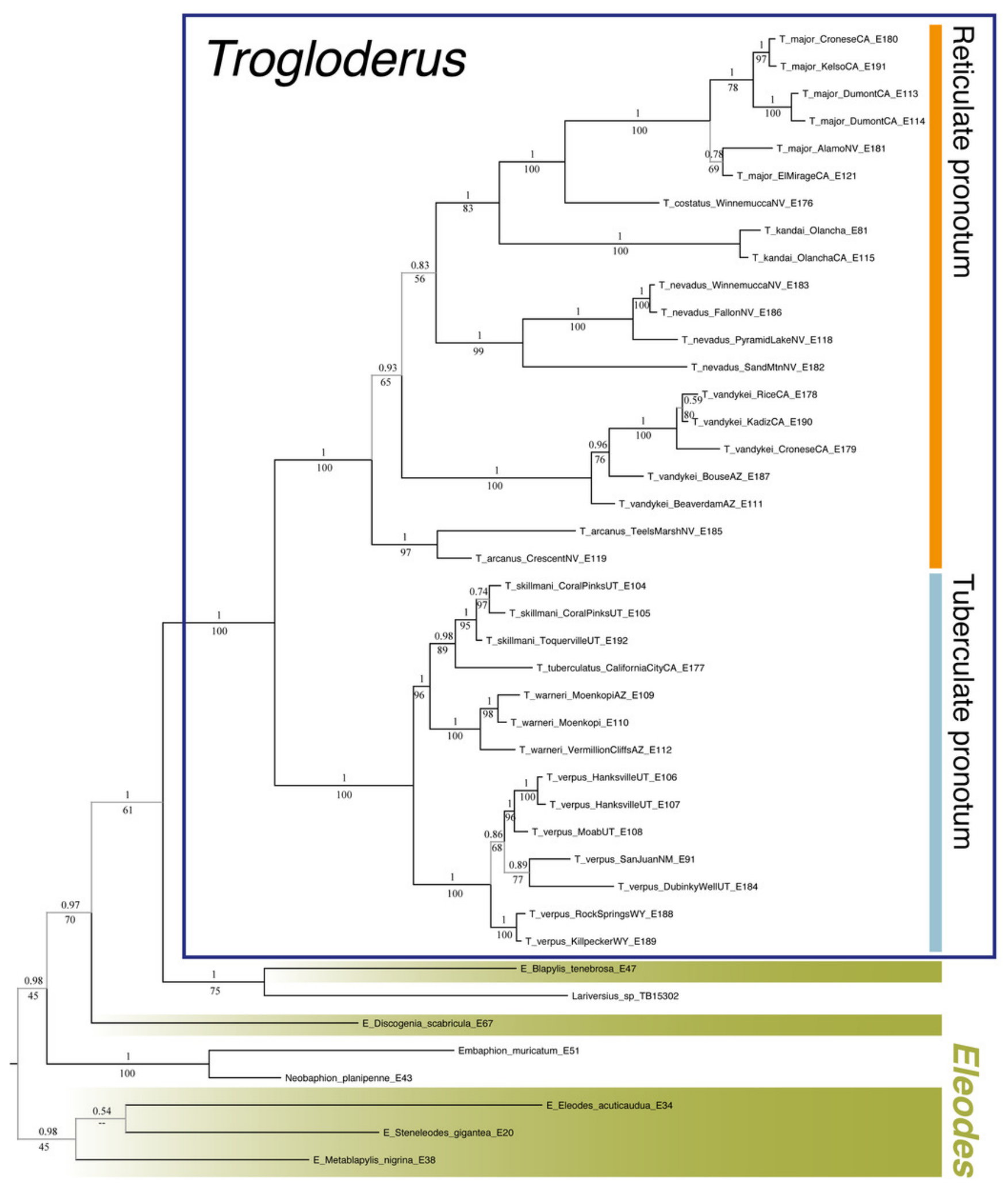




\section{Figure 12}

Diversification estimates for Trogloderus.

(A) Timetree generated from BEAST showing inferred median node ages. (B) Same showing 95\% highest posterior density for node ages. (C) Timetree generated from RelTime showing inferred median node ages. (D) Same showing 95\% confidence intervals for node ages. 

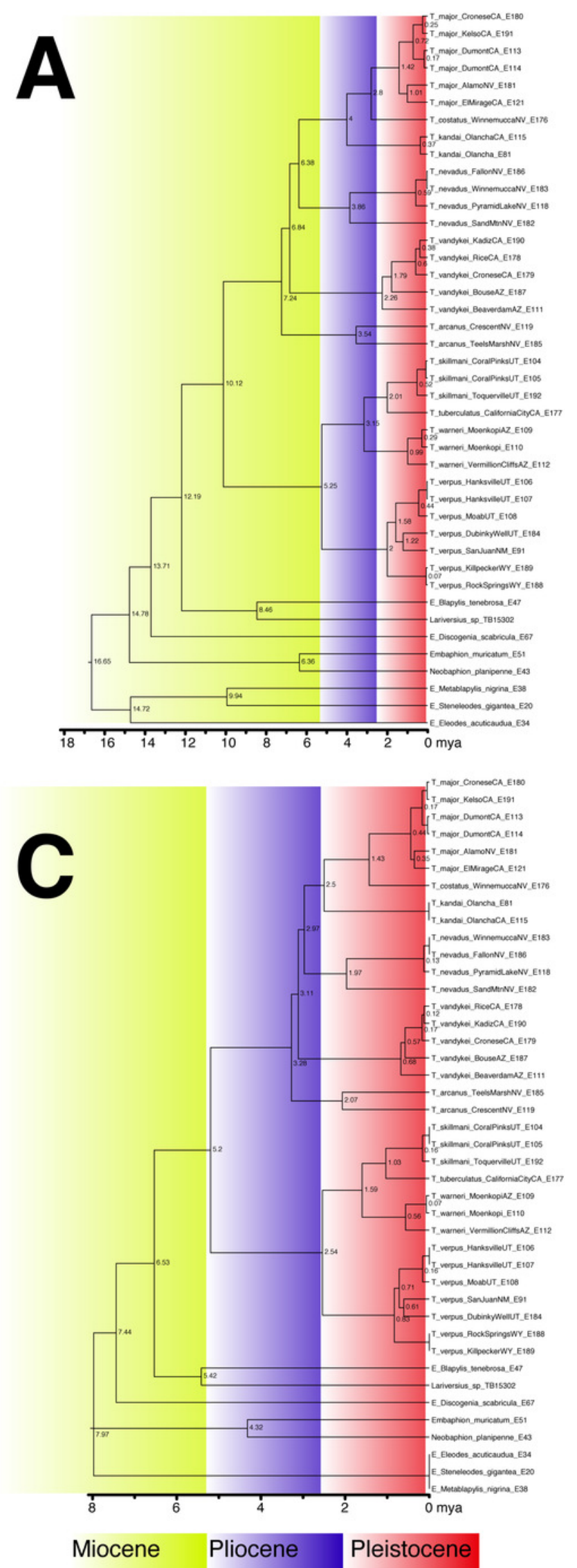
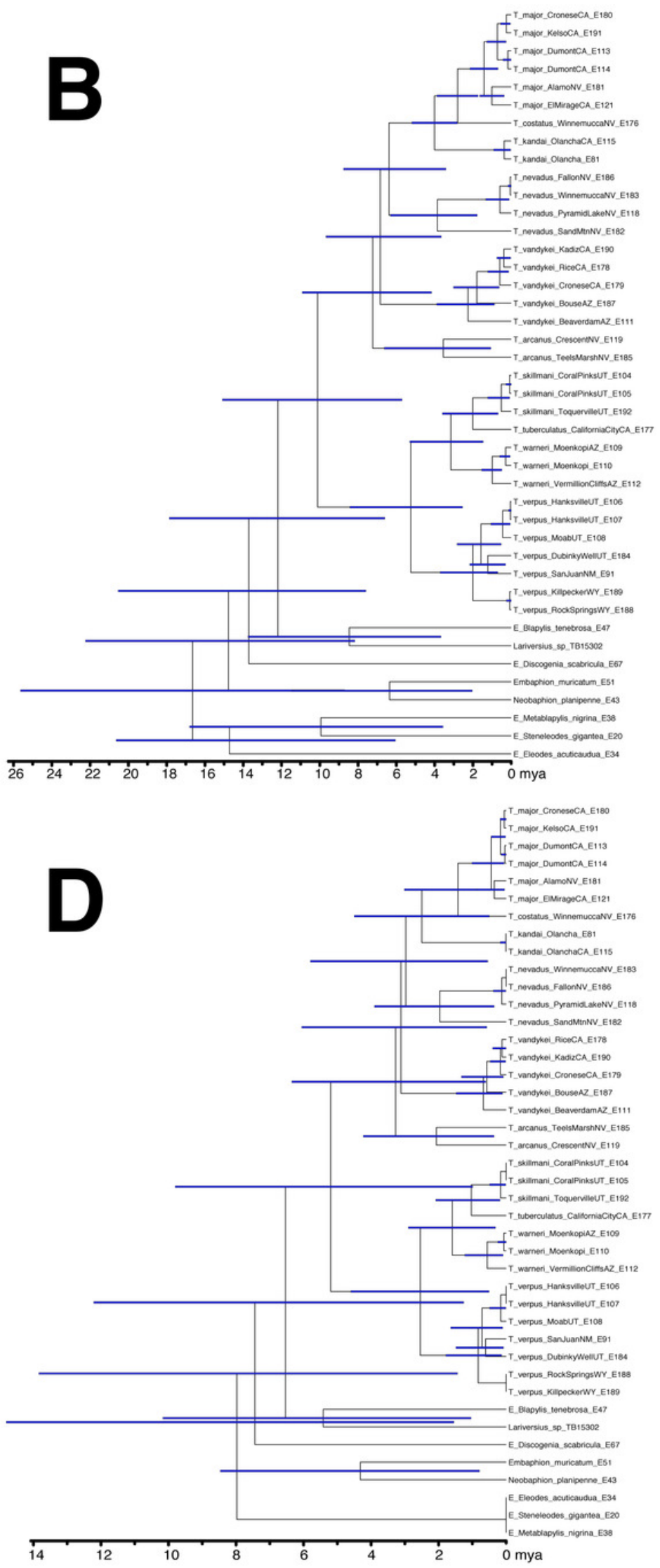
Figure 13

Historical biogeographic estimation of Trogloderus.

Generated from BioGeoBEARS using the DEC+J model. Nodes colored by inferred most likely biogeographic region. 
CP Colorado Plateau

LT Lahontan Trough

GB Great Basin

Ov Owens Valley

MO Mojave Desert

WD Widespread

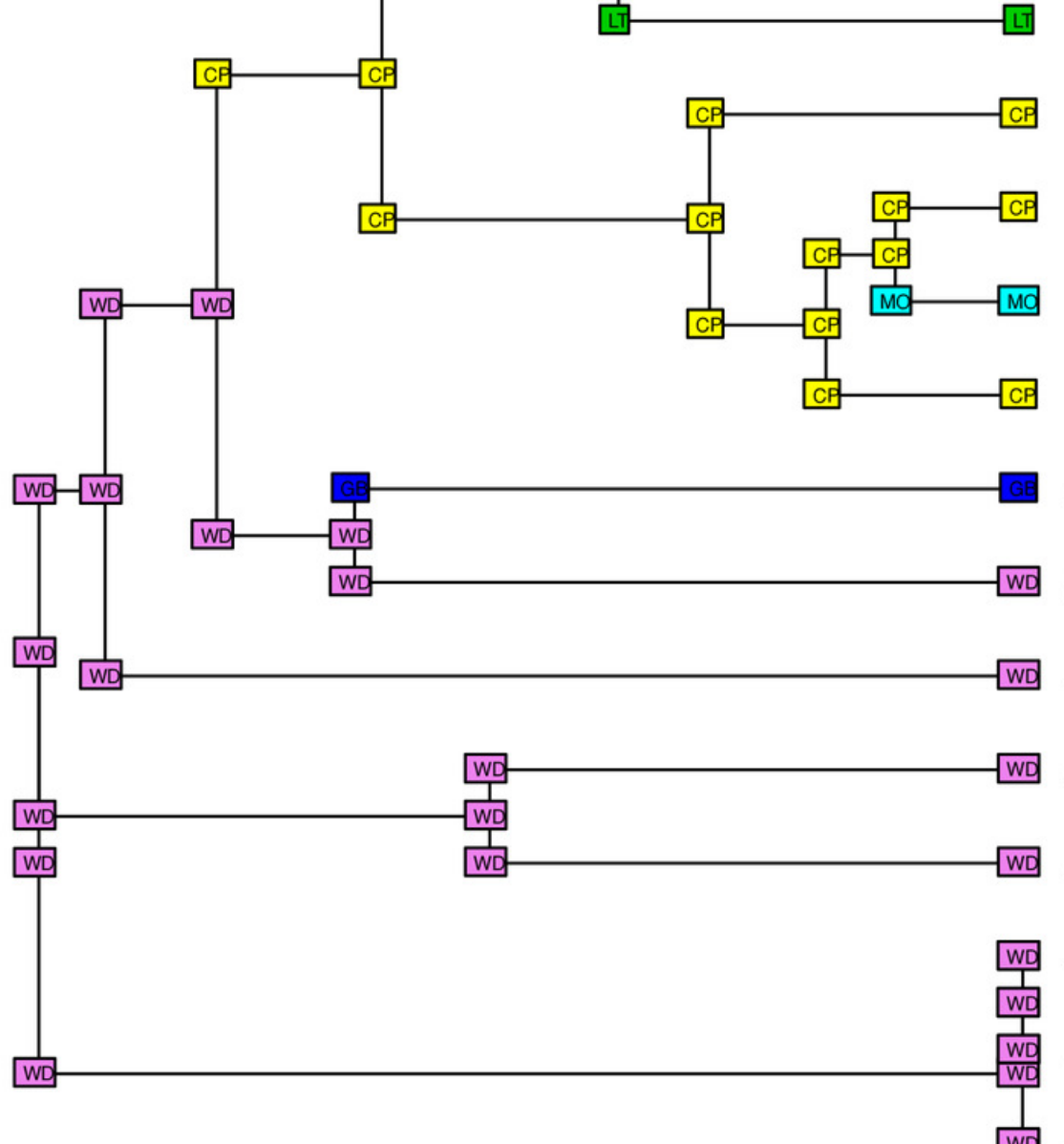

WD. (Blapylis) tenebrosa

WD E. (Discogenia) scabricula

WD Neobaphion planipenne

WD Embaphion muricatum

E. (Steneleodes) gigantea

E. (Eleodes) acuticauda

w0. (Metablapylis) nigrina

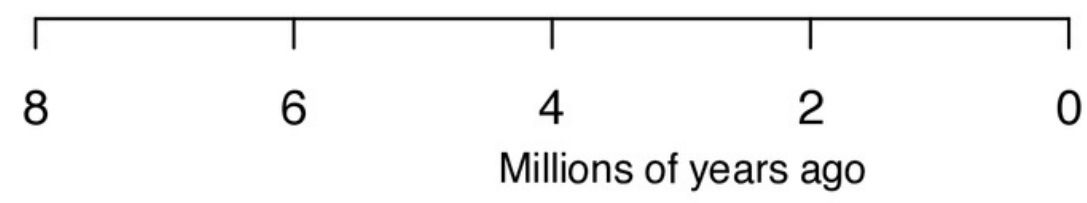




\section{Table $\mathbf{1}$ (on next page)}

Loci and associated primers used in this study. 
1 Table 1.

2 Loci and associated primers used in this study.

3

4

\begin{tabular}{|c|c|c|c|}
\hline Locus & $\begin{array}{l}\text { Alignment } \\
\text { length (bp) }\end{array}$ & Primers used & Primer source \\
\hline Cytochrome c oxidase subunit 1 (COI) & 792 & $\begin{array}{l}\text { Jerry (F) } \\
\text { Pat (R) }\end{array}$ & Simon et al. 1994 \\
\hline Cytochrome c oxidase subunit 2 (COII) & 700 & $\begin{array}{l}\text { F-lue }(F) \\
9 b(R)\end{array}$ & Whiting 2002 \\
\hline $12 \mathrm{~S}$ mitochondrial ribosomal RNA (12S) & 350 & $\begin{array}{l}\text { SR-J-14233 (F) } \\
\text { SR-N-14588 (R) }\end{array}$ & Simon et al. 1994 \\
\hline 28S ribosomal RNA (28S) & 1030 & $\begin{array}{l}\text { NLF184 (F) } \\
\text { D3ar (R) }\end{array}$ & $\begin{array}{l}\text { Van der Auwera et al. } 1994 \\
\text { Maddison } 2008\end{array}$ \\
\hline Histone 3 (H3) & 361 & $\begin{array}{l}\operatorname{Haf}(F) \\
\operatorname{Har}(R)\end{array}$ & Colgan et al. 1998 \\
\hline Wingless (wnt) & 474 & $\begin{array}{l}\text { wg550f (F) } \\
\text { wfAbrZ (R) }\end{array}$ & Wild and Maddison 2008 \\
\hline
\end{tabular}

5 